\title{
Sovereign rating actions and the implied volatility of stock index options
}

\section{Article}

\section{Accepted Version}

Creative Commons: Attribution-Noncommercial-No Derivative Works 4.0

Tran, V., Alsakka, R. and ap Gwilym, O. (2014) Sovereign rating actions and the implied volatility of stock index options. International Review of Financial Analysis, 34. pp. 101-113. ISSN 1057-5219 doi: https://doi.org/10.1016/j.irfa.2014.05.010 Available at https://centaur.reading.ac.uk/88880/

It is advisable to refer to the publisher's version if you intend to cite from the work. See Guidance on citing.

To link to this article DOI: http://dx.doi.org/10.1016/j.irfa.2014.05.010

Publisher: Elsevier

All outputs in CentAUR are protected by Intellectual Property Rights law, including copyright law. Copyright and IPR is retained by the creators or other copyright holders. Terms and conditions for use of this material are defined in the End User Agreement.

\section{www.reading.ac.uk/centaur}

\section{CentAUR}

Central Archive at the University of Reading

Reading's research outputs online 


\title{
Sovereign rating actions and the implied volatility of stock index options
}

\author{
Vu Tran ${ }^{\mathrm{a}}$, Rasha Alsakka ${ }^{\mathrm{b}, *}$, Owain ap Gwilym ${ }^{\mathrm{b}}$ \\ ${ }^{a}$ School of Management, Swansea University, Swansea, SA28PP \\ ${ }^{b}$ Bangor Business School, Bangor University, Bangor LL57 2DG, UK
}

This version: $4^{\text {th }}$ April 2014

\begin{abstract}
This paper examines the interaction between the equity index option market and sovereign credit ratings. S\&P and Moody's signals exhibit strong impact on option-implied volatility while Fitch's influence is less significant. Moody's downgrades reduce the market uncertainty over the rated countries' equity markets. Strong causal relationships are found between movements in the option-implied volatility and all credit signals released by $\mathrm{S} \& \mathrm{P}$ and Fitch, but only actual rating changes by Moody's, implying differences in rating agencies' policies. The presence of additional ratings tends to reduce market uncertainty. The findings highlight the importance of rating information in the price discovery process and offer policy implications.
\end{abstract}

JEL classification: G14; G15; G24

Keywords: Sovereign ratings; Implied volatility; Stock index options; Price discovery process.

\footnotetext{
* Corresponding author. Tel.: +44 (0) 1248 383571. E-mail address: r.alsakka@bangor.ac.uk
} 


\title{
Sovereign rating actions and the implied volatility of stock index options
}

\author{
This version: $4^{\text {th }}$ April 2014
}

\begin{abstract}
This paper examines the interaction between the equity index option market and sovereign credit ratings. S\&P and Moody's signals exhibit strong impact on option-implied volatility while Fitch's influence is less significant. Moody's downgrades reduce the market uncertainty over the rated countries' equity markets. Strong causal relationships are found between movements in the option-implied volatility and all credit signals released by S\&P and Fitch, but only actual rating changes by Moody's, implying differences in rating agencies' policies. The presence of additional ratings tends to reduce market uncertainty. The findings highlight the importance of rating information in the price discovery process and offer policy implications.
\end{abstract}

JEL classification: G14; G15; G24

Keywords: Sovereign ratings; Implied volatility; Stock index options; Price discovery process. 


\section{Introduction}

Credit rating agencies (CRAs) provide valuable functions in assessing credit risk and in financial market development (e.g. Coffee, 2006; Bank of England, 2011). However, "hardwiring" and "cliff effects" of credit rating signals have been under scrutiny during the global financial crisis (International Monetary Fund (IMF) 2010; Bank of England, 2011). In response, rating-based rules and guidelines have been under consideration to be dismissed (e.g. US Securities and Exchange Commission (SEC) 2011a, b), and a new CRA regulation regime has been established in the European Union (EU).

This paper investigates the interaction between sovereign rating news and the equity index option market. This market is typically inhabited by institutional informed traders (see Chakravarty et al., 2004; Chen et al., 2005; Jin et al., 2012). Much literature identifies that the derivative markets play a leading role in the price discovery process (e.g. Blanco et al., 2005; Acharya and Johnson, 2007; Avino et al., 2013). Therefore, the dynamics of derivative markets can provide important information regarding the credit quality of underlying entities. In 2011, the turnover of equity index options traded on organised exchanges over the world was US\$ 166 trillion (Bank for International Settlements, 2012). The equity index option market is the second largest segment of exchange-traded financial derivative markets, after interest rate derivatives. Given the prominence of both derivative markets and CRAs, interesting questions about the interaction between the index option market and credit rating actions can be raised. Such investigations must also consider CRAs' 'through the cycle' rating philosophy, which implies that credit ratings are stable and possibly lag behind option market indicators. ${ }^{3}$

\footnotetext{
${ }^{1}$ Credit ratings are embedded into regulations and investment mandates thus making them more influential.

${ }^{2}$ Sudden difficulties caused by rating downgrades because many market participants are forced to sell-off securities that are downgraded below certain rating thresholds.

${ }^{3}$ Outlook and watch procedures are expected to alleviate the lag to some extent because they help CRAs to avoid rating reversals and to mitigate the tension between rating accuracy and rating stability.
} 
Volatility is of crucial interest to institutional investors who hold large international diversified portfolios. In terms of economic mechanisms, this paper's analysis is motivated by prior literature on the links between sovereign credit risk and the corporate and financial sectors' overall risk, equity market performance and uncertainty (e.g. Arellano, 2008; Acharya et al., 2014; Bedendo and Colla, 2013; Borensztein et al., 2013; Gennaioli et al., 2014). This is discussed further in Section 2.2.

To the best of our knowledge, there is no prior investigation of the relationship between credit ratings and option markets. We address a gap in knowledge about the relative information content from the two sources. Moreover, we demonstrate the importance of sovereign rating information in the context of first-mover as well as additional rating signals. Several robustness checks are performed using non-parametric approaches and Monte Carlo experiments. The paper highlights differences in rating policy and varying influence of rating signals from the largest three CRAs, namely Moody's, S\&P, and Fitch.

The main findings are summarised as follows. Firstly, sovereign rating news has a significant impact on the option market in various respects depending on the type of news and across CRAs. Secondly, there is strong evidence of causality between movements in the option market and all types of rating signals from S\&P and Fitch, but only actual rating changes from Moody's, thus highlighting differences in rating policies. Moreover, the market reactions to S\&P and Moody's signals infer that additional ratings are still informative and help reduce market uncertainty. Such results shed light on the price (credit information) discovery process. Finally, the findings contribute to the debate surrounding the regulation of CRAs and their ratings.

The remainder of the paper is organised as follows. The next section reviews related literature, Section 3 describes the data, Section 4 discusses the research hypotheses and methodologies, Section 5 presents the empirical results and Section 6 concludes the paper. 


\section{Literature review}

\subsection{Credit ratings and regulation}

The rating industry performs a gate-keeping role for international capital markets (e.g. Coffee, 2006). Issuers seek ratings to improve the marketability of their financial obligations, and/or to increase their trustworthiness to business counterparties. Investors use ratings as a cost-effective indicator of securities' credit risk. Credit ratings provide three essential economic functions: information production, monitoring, and certification. Firstly, CRAs mitigate the fundamental adverse selection problem between borrowers and investors. Through the gathering and analysis of data relating to creditworthiness, CRAs mitigate informational asymmetry and adverse selection problems, decrease the risk premium of a debt issue, and hence increase the liquidity of assets (Bank of England, 2011).

Secondly, rating-based guidelines and rules perform a monitoring role and mitigate principal-agent problems. Moreover, by signalling a potential downgrade via negative outlooks or watch lists, CRAs also encourage an issuer to improve its creditworthiness (IMF, 2010). To the extent that investors respond to rating changes by adjusting their portfolios, such negative rating announcements impose the implicit threat on issuers that failure to act will degrade their ability to refinance in the future.

Thirdly, CRAs provide a certification function for fund managers, regulators, central banks, and other market participants in distinguishing between securities with different risk characteristics, and specifying terms and conditions in financial contracts (IMF, 2010). Examples of credit ratings' certification function can be found in many aspects of investments (e.g. Cantor et al., 2007). The certification function is found in regulatory capital requirements for insurance firms (Campbell and Taksler, 2003; Coffee, 2006), commercial banks and other financial institutions (Basel Committee on Banking Supervision, 2011), and in the US SEC's regulatory references (see SEC 2011a, b). 
The fact that credit ratings have been "hard-wired" into regulations has widened their influence. Regulators use credit ratings to restrict public managed funds to invest in debts below certain levels of credit ratings, usually the investment-speculative threshold. The motivations for using credit ratings as an instrument for market regulation are: (i) aiming at financial soundness via establishing prudential minimum credit quality for portfolio holdings (e.g. IMF, 2010; White, 2010); (ii) encouraging a minimum credit quality of securities issuance to protect investors (e.g. Coffee, 2006).

CRAs have faced extensive scrutiny for being too lax in rating structured securities, and this is widely regarded as a contributing factor to the US subprime crisis (e.g. White, 2010; Bank of England, 2011). In response, several regulatory proposals to monitor CRAs have been approved or are under consideration, while rating-based rules and guidelines have been under consideration to be dismissed. Many G-20 countries have introduced or are in the process of implementing new regulatory changes on CRAs (Bank of England, 2011). In the US, the Dodd-Frank Act requires thorough revisions of the role of credit ratings in the US regulatory framework. For instance, in March and April 2011, SEC proposed amendments removing references to credit ratings in the Investment Company Act of 1940 and the Securities Exchange Act of 1934, which are the legal backbone of the US financial system (SEC, 2011a, b). In November 2012, one rule, which regulates Business and Industrial Development companies who operate under state statutes, among six proposals in SEC (2011a) was adopted. As at March 2014, the remaining proposals are still under consideration and have not been legally approved.

CRAs are also accused of precipitating the EU sovereign debt crisis by issuing multiple downgrades on Greece, Ireland, Portugal, Spain, and Italy. Politicians in the EU have called for further regulation to improve quality and transparency in sovereign ratings. Since 2012, all CRAs operating in Europe are required to register with the European Securities and 
Markets Authority and to observe demanding rules which incorporate the International Organization of Securities Commissions' Code of Conduct Fundamentals for Credit Rating Agencies (revised in 2008).

\subsection{Economic and market impact of sovereign ratings}

Prior literature shows that sovereign credit risk can spill-over to corporate and financial sectors, cross-border investments, and the national economy in numerous ways. Arellano (2008) shows that a sovereign default triggers significant surges in the volatilities of interest rates, consumption and output. Borensztein el al. (2013) and Bedendo and Colla (2013) show that corporate credit risk and borrowing costs are strongly correlated with the evolution of sovereign credit risk. Bedendo and Colla (2013) suggest that a government in financial distress is more likely to "transfer risk" to corporates by increasing taxation, imposing foreign exchange controls, or expropriating private investments.

Acharya et al. (2014) illustrate a strong relation between sovereign and banks' risks. Deterioration in sovereign creditworthiness significantly triggers increases in banks' risks not only because of their large holdings of government bonds but also due to the reduction in the value of government guarantees to banks. For example, in 2011-2012, numerous European banks were downgraded by CRAs who explained these downgrades by deteriorations in their governments' financial capacities and willingness to bailout these entities. Moreover, the Committee on the Global Financial System (2011) highlights how the European sovereign debt crisis affected banks' ability to raise funding. Collateral damage, risk aversion, and crowding-out effects are crucial channels via which deteriorations in sovereign creditworthiness strain banks' funding conditions. The funding difficulties, in turn, force the banks to squeeze the credit supply for the economy and consequently threaten the prospects of the national economy (Gennaioli et al., 2014). 
Another strand of literature presents evidence that sovereign credit rating actions are influential in many financial markets. Sovereign credit ratings are a major factor influencing sovereign yield spreads (e.g. Afonso et al., 2012). Generally, the impact of rating news in the debt market is asymmetric. Negative rating news imposes significant impact while the influence of positive actions is much more muted. Moreover, sovereign rating news spills over to other sovereign bond yields (e.g. Gande and Parsley, 2005; Arezki et al., 2011).

Equity markets are also affected by sovereign rating news in a similar asymmetric manner. Kaminsky and Schmukler (2002) find that rating changes (on emerging sovereigns) affect the rated countries' stock indices. Ferreira and Gama (2007) find that (S\&P's) sovereign rating changes of one country impose an asymmetric impact on the stock markets of other countries. Sovereign rating downgrades cause negative reactions whereas upgrades have no significant impact. Arezki et al. (2011) reveal that sovereign downgrades have significant spill-over effects not only across (European) countries but also across financial markets, i.e. sovereign credit default swaps (CDS), banking, insurance, and stock markets, during the period overlapping the European sovereign debt crisis. Alsakka and ap Gwilym (2013) find that both positive and negative credit news affects not only the rated country exchange rate but also spills over to other countries' exchange rates. The market reactions vary across CRAs' signals.

For derivatives markets, prior literature on the impact of rating actions is restricted to examining the CDS market. Norden and Weber (2004) find significant increases in (corporate) CDS spreads in advance of negative (corporate) rating events implying that the CDS market anticipates negative rating events. Results for positive rating events are much less significant. Afonso et al. (2012) find that the CDS market reacts to negative sovereign rating events while the reaction to positive events is much more muted. Additionally, rating downgrades seem to be anticipated by the CDS market. 
The above issues suggest that strong economic linkages exist between sovereign rating actions and equity market performance and thus market-wide volatility. However, the relationship between sovereign ratings and equity options (or implied volatility) has been ignored by prior literature. We address a gap in knowledge about the relative information content from the two sources.

Given the prior evidence on the economic links between sovereign risk and uncertainty of the national economy, sovereign rating announcements are expected to impact market participants' risk expectations. However, the option market (or implied volatility) will not necessarily react to negative (positive) rating news in a negative (positive) direction like other financial markets, as evidenced in e.g. Kaminsky and Schmukler (2002), Gande and Parsley (2005), Ferreira and Gama (2007), Arezki et al. (2011). Beber and Brandt (2006, 2009) reveal that scheduled macroeconomic news always reduces financial market uncertainty regardless of whether the news is more negative or more positive compared to prior expectations. ${ }^{4}$ The higher ex-ante uncertainty over the content of the macroeconomic news, the larger the drop in the market uncertainty when the news is released.

Of course, credit rating news is not scheduled. However, market participants often consult with multiple CRAs (e.g. Cantor et al., 2007; Bongaerts et al., 2012). Therefore, it is rational for investors to expect actions from the other CRAs after a rating announcement from a 'first mover' CRA. We, thus, expect variation in the market reaction across CRAs. Prior literature also shows that there are variations in other market reactions to rating news released by different CRAs (e.g. Alsakka and ap Gwilym, 2013).

The option market is typically inhabited by institutional, informed traders (e.g. Chakravarty et al., 2004; Chen et al., 2005; Jin et al., 2012). Derivative markets also play a

\footnotetext{
${ }^{4}$ While Beber and Brandt (2006) employ the second moment of option-implied state-price-densities to proxy the (US Treasury) market uncertainty, Beber and Brandt (2009) use (US T-bonds, S\&P 500 index, Eurodollar, stocks) options-implied volatilities.
} 
leading role in the price discovery process (e.g. Blanco et al., 2005; Acharya and Johnson, 2007; Avino et al., 2013). Sovereign credit issues are less opaque to observe compared to those of corporate, banks and other issuers. Therefore, the market reactions of implied volatility to sovereign rating signals could be in either positive or negative directions.

\section{Data}

This study is based on an unbalanced panel dataset which covers 24 countries during the period from January 2000 to April 2012. The availability of traded stock index options determines the sample size and sample periods, i.e. we include all countries with data available for stock index options, except for 5 countries without any rating actions during the options sample period (Canada, Malaysia, Norway, Sweden, Switzerland). ${ }^{5}$ Table 1 lists the countries and the sample periods.

\subsection{Credit ratings}

Rating information is collected from Moody's, S\&P, and Fitch publications. This dataset consists of daily observations of long-term foreign-currency credit ratings, outlook and watch status of sovereigns rated by these three leading CRAs. Fig. 1 presents the distribution of daily ratings of sovereigns for each CRA. None of the 24 sovereigns were rated lower than BBB- (Baa3) by S\&P, Fitch, and Moody's during the sample period. About $60 \%$ of the daily observations are in the triple-A rating category, and $2 \%-5 \%, 4 \%-7 \%$ and around $3.5 \%$ are at $\mathrm{AA}+/ \mathrm{Aa} 1, \mathrm{AA} / \mathrm{Aa} 2$ or $\mathrm{AA}-/ \mathrm{Aa} 3$ rating categories. These proportions reflect the developed nature of the sample countries, which obviously coincides with the development of liquid stock index option markets.

\footnotetext{
${ }^{5}$ Greece is excluded due to very low trading volume for stock index options. Options on Portugal PSI 20 and Ireland ISEQ were not traded during the sample period.
} 
We convert sovereign ratings to numerical scores within a 31-point comprehensive credit rating (CCR) scale in order to capture information on both actual ratings and outlook/watch procedures. On the CCR scale, rating symbols are converted as follows: $\mathrm{AAA} / \mathrm{Aaa} \equiv 31, \mathrm{AA}+/ \mathrm{Aa} 1 \equiv 28, \mathrm{AA} / \mathrm{Aa} 2 \equiv 25 \ldots \mathrm{BBB}-/ \mathrm{Baa} 3 \equiv 4$, lower than $\mathrm{BBB}-/ \mathrm{Baa} 3 \equiv 1$. Adjustments for (positive/negative) outlook and watch announcements are made by adding \pm 1 and \pm 2 , respectively, on the CCR scale.

There is non-linearity in the rating scale, which means that the differences between rating levels are not equal. For example, a downgrade from AAA to AA+ or a downgrade from the investment grade to the junk grade have different implications to a downgrade from A to A-. Historical observations on default rates across rating categories also suggest such non-linearity (see e.g. IMF, 2010 and many others). In order to control for this, we employ a logit-transformation of the rating scale, constructed as follows:

$$
L C C R=\ln \left[\frac{C C R}{32-C C R}\right]
$$

Prior literature has used a logarithm transformation of the rating scale (e.g. Alsakka and ap Gwilym, 2013), but their transformation is different to ours. Their transformation gives the highest weight for rating changes on AAA and near bankruptcy issuers and the lowest weight for rating changes near the investment-speculative boundary. In contrast, our transformation gives greatest weights for rating changes on AAA and those near the investment-speculative threshold.

There are several reasons why we adopt this particular log-transformation of the rating scale. Firstly, the speculative threshold is considered as very critical among rating users. For example, the U.S. Investment Company Act of 1940 restricts pension funds and municipalities to the investment-grade range. Insurance firms also rely heavily on assets with investment-grade ratings because regulatory capital reserves increase significantly for 
speculative assets (Campbell and Taksler, 2003). The speculative threshold is one of the most critical concerns to investors (e.g. Cantor et al., 2007; Bongaerts el al., 2012). Therefore, it is reasonable to assign more weight to rating changes around this threshold. Secondly, there is no rating observation lower than BBB- during the sample period. Thirdly, it is reasonable that rating changes at the top of the scale are also given more weight (e.g. as evidenced by the reactions to sovereign downgrades of France, UK, and USA in 2011-2013).

Outlook and watch signals are defined as follows. Negative watch signals include placing a sovereign on watch for possible downgrade and withdrawing watch status for possible upgrade (without an actual upgrade). Positive watch signals include placing a sovereign on watch for possible upgrade and withdrawing watch status for possible downgrade (without an actual downgrade). Negative outlook signals include changes to negative outlook from stable/positive outlook, and changes to stable outlook from positive outlook (without any rating change). Positive outlook signals include changes to positive outlook from stable/negative outlook, and changes to stable outlook from negative outlook (without any rating change). During the period, there are 13 (29), 10 (16), 9 (19) positive (negative) outlook announcements for the sample countries made by S\&P's, Moody's, and Fitch, respectively. The corresponding figures of watch actions are 11 (11), 9 (11), and 3 (3) (see Table 2).

Table 2 presents the sovereign credit rating events for each CRA. In total, there are 78 (126) positive (negative) rating events released by the CRAs during the sample periods for the selected sovereigns. S\&P released the most rating news with 33 positive and 56 negative signals. There are 26 (39) positive (negative) rating announcements by Moody's while the figures are 19 (31) by Fitch. Almost all of the rating events are "clean" i.e. are not followed by same direction rating signals from other CRA(s) within at least 1 week. There are only 12 rating events which involve more than one CRA taking action on the same sovereign within 
one week. This is in support of the view that each CRA has its own policy on rating timeliness and rating stability (e.g. Alsakka and ap Gwilym, 2010). ${ }^{6}$

The majority of rating events are single, whereby they do not involve both a rating downgrade/upgrade and outlook or watch signals, simultaneously. There are only 2/65 rating events made by Moody's, and 1/50 by Fitch which are such multiple-rating events. S\&P have released no such multiple-rating events during the sample periods. The majority of rating events are also within 3-point signals in the CCR scale which mean an outlook or watch announcement or a 1-notch downgrade/upgrade in isolation. There are only 3/89 rating events made by S\&P, $6 / 65$ by Moody's, 3/50 by Fitch which are multiple-notch downgrades/upgrades.

\subsection{Implied volatility}

Data on 30-day call option- implied volatility (IV) upon the countries' stock indices is collected from DataStream. The primary sources of data on premium, strike price, and maturity of the call options are the exchanges where these options are traded. The IV is estimated via the Black-Scholes model (for European style contracts) and the Cox-RossRubinstein binomial model (for American style contracts). An interpolation is calculated based on four series of call option contracts: two nearest to at-the-money and two nearest to 30-day maturity. We use at-the-money contracts to mitigate the effects of skewness and smile. ${ }^{7}$ Also, the 30 -day maturity means that the IV estimates short-term expected volatility which coincides with the short-term horizon of the rating watch procedure.

There are 35,683 daily observations of 30-day implied volatility. Fig. 2 presents the distribution of the IV. During the sample periods, there are 315 observations where IV is

\footnotetext{
${ }^{6}$ Market participants value both rating accuracy and stability. Rating stability is appreciated by many market participants, especially regulators, pension funds, mutual funds who often follow passive investment strategies. In these cases, a precisely accurate but wildly volatile rating system induces unbearably high transaction costs. ${ }^{7}$ Prior studies show that IVs are usually much higher for deep in the money and deep out of the money option contracts compared to at-the-money contracts, and this is known as the "smile" pattern.
} 
greater than $100 \%$ in Hungary (14/01/2003-16/6/2003), Poland (7/2001, 10-11/2001, 28/2002, 11/2002), and Russia (10/2008-4/2009). All (most) of these observations are associated within 1 month to at least one observation of absolute value of the underlying index return larger than $1 \%(3 \%) .54 \%$ of the observations are associated with at least one observation of absolute value of the index return larger than $10 \%$. There were nine rating signals on the three sovereigns during these periods. Therefore, we do not exclude these observations in order to avoid possible information loss. Moreover, equivalent empirical investigations based on excluding the 315 observations produce qualitatively similar results (discussed further in Section 5).

Our main interest is in the dynamics of the IV, and Fig. 3 presents the distribution of daily changes in the IV. The changes are very much centred around zero with a mean of 0.0000451, median of 0 , and standard deviation of $0.031 .^{8}$

\section{Hypotheses and methodological framework}

\subsection{Hypothesis I: Influence of rating news in the option market}

$\mathrm{H}_{0}$ : Credit rating news does not impose a discernable influence on the option market. Therefore, changes in the IV around any type of rating event are not statistically different from zero.

In this stage, we use a standard event study. The event window is one week before and after rating events in order to mitigate any information contamination. Three intervals are defined as $[-5,-1],[-1,1],[1,5] . \mathrm{t}=0$ denotes the day when a rating announcement is released. The $[-1,1]$ window is chosen rather than $[0,1]$ in order to control for any time zone issue. ${ }^{9}$ In addition, we only include clean events which are not followed or overlapped by rating

\footnotetext{
${ }^{8}$ We exclude 23 observations of the daily $\Delta \mathrm{IV}$ whose absolute values are greater than $50 \%$, accounting for $0.067 \%$ of total observations.

${ }^{9}$ Please note that our $[-1,1]$ window is equivalent to $[0,1]$ in other studies which examine financial assets returns because an asset return for day 0 incorporates information on the asset's prices in day -1 and day 0 .
} 
announcement(s) on the same sovereign by another CRA(s) within at least 1 week in order to further avoid information contamination. ${ }^{10}$ With such a short distance in time (i.e. one week), it is highly plausible that two (or more) CRAs are reacting to the same underlying credit issue. Rating signals from different CRAs are pooled together in order to increase the numbers of events and hence the power of the testing procedure. ${ }^{11}$

Prior literature shows that the option market is efficient and there is no significant evidence of forecastability of implied volatility. Konstantinidi et al. (2008) use numerous economic indicators in several econometric models in an attempt to forecast the evolution of US and European option implied volatilities, but none of these variables is significant and the adjusted $\mathrm{R}^{2}$ values of all the models are very near to zero. Moreover, out-of-sample forecasting evidence mostly favours the random walk model for evolution of the IVs. Jiang and Tian (2012) also support the random walk hypothesis for modelling the implied volatility extracted from S\&P 500 index options. Therefore, we examine changes in the IV instead of modelling an abnormal element in the changes. ${ }^{12}$

In order to avoid any possible bias due to the distribution of the sample mean of the $\Delta \mathrm{IV}$ due to the limited numbers of rating events, non-parametric tests are employed as robustness checks. The non-parametric tests are sign- and Wilcoxon tests, testing whether the medians of the $\Delta \mathrm{IV}$ during the time windows are significantly different to zero.

\footnotetext{
${ }^{10}$ Only for this event study, we exclude 12 'unclean' rating events (mentioned in Section 3.1). Later investigations are based on all rating events.

${ }^{11} \mathrm{We}$ are aware that the market reaction might vary across CRAs. The potential for varying reactions is examined by later methodologies.

${ }^{12}$ We also conducted Durbin-Watson and Breusch-Godfrey tests for the random walk of $\mathrm{IV}_{\mathrm{t}}$ in our sample. For most countries, the null hypothesis that $\mathrm{IV}_{\mathrm{t}}$ follows a random walk is accepted. The exceptions are Austria, France, Japan, Russia, Taiwan and USA. Results are available on request.
} 


\subsection{Hypothesis II: Varying impact across CRAs' actions}

$\mathrm{H}_{0}$ : The impact of rating signals on the option market is similar across CRAs.

Varying market reactions to rating news from different CRAs are reported in the literature (e.g. Bongaerts et al., 2012; Alsakka and ap Gwilym, 2013). The following regression is estimated:

$$
\Delta \mathrm{IV}_{\mathrm{i}, \mathrm{s}}=\alpha+\beta^{*} \Delta \mathrm{LCCR}_{\mathrm{i}, \mathrm{t}}+\gamma^{*} \mathrm{CCR}_{\mathrm{i}, \mathrm{t}}+\theta^{*} \mathrm{Co}+\psi^{*} \mathrm{Y}+\varepsilon_{\mathrm{i}, \mathrm{t}}
$$

$\Delta \mathrm{IV}_{\mathrm{i}, \mathrm{s}}$ represents changes in the implied volatility for sovereign $i$ during time windows $s$ around credit signals from each CRA. Time windows are restricted to 3 months before- and after- credit signals. Specifically, $[-66,-22],[-22,-5],[-5,-1]$ capture the market movements preceding rating news by 3 months, 1 month and 1 week, respectively; $[-1,1]$ conveys the market movements when rating news is released; $[1,5],[5,22],[22,66]$ capture market movements after rating news during 1 week, 1 month, 3 months later.

$\triangle \mathrm{LCCR}$ measures the sovereign credit signals, representing the 1-day change in the log-transformation of the CCR for sovereign $i$ at event date $t$. CCR is the comprehensive credit rating from each CRA, which is included as an explanatory variable to control for macroeconomic news and other fundamentals of the rated sovereigns (e.g. Prati et al., 2012; Alsakka and ap Gwilym, 2013). As macroeconomic and other fundamentals are determinants of sovereign ratings, the inclusion of ratings, in addition to country and year dummies, helps control for the likelihood that IV might be more volatile in countries with weak macroeconomic conditions. Thus, including CCR reduces any potential omitted variable bias.

Co and $\mathrm{Y}$ are full vectors of country and year dummies. For each country and year in our data, we define one dummy variable. In total, there are 24 country dummies and 13 year dummies (2000-2012).

Estimations of Eq. (1) are based on event days plus a country-matched random sample, drawn from the full sample after excluding non-event observations within the time 
windows around rating events, in order to mitigate rating clustering and market noise issues (see Ferreira and Gama, 2007). ${ }^{13}$ It is noteworthy that the sample consists of observations on non-consecutive days that may be very distant from each other.

In order to consider varying impacts across CRAs' actions (if any), we estimate Eq. (1) for each CRA separately. For each CRA, there are three separate estimations for different types of signals (i.e. actual rating, outlook, watch announcements) in order to investigate the asymmetric market behaviour (if any). For ease of interpretation, the absolute value of $\triangle \mathrm{LCCR}$ is used.

Furthermore, we perform Monte Carlo experiments as robustness checks by repeating the country-matched random sampling 10,000 times. Each time, our sample consists of a number of event observations plus the same number of random non-event observations. Based on this sample, regressions for the CRAs are run and the averages of estimated coefficients across the 10,000 times are reported (see Gande and Parsley, 2005).

\subsection{Hypothesis III: Causality between sovereign rating and IV}

$\mathrm{H}_{0}$ : Neither sovereign rating actions nor IV changes cause changes in the other variable. Given the leading role of derivatives markets (Blanco et al., 2005; Acharya and Johnson, 2007; Jin, et al., 2012; Avino et al., 2013), we expect some evidence that the option market leads rating actions. Nonetheless, the lead-lag relationship between the market and ratings assigned by different CRAs could be different since the timeliness and policies of each CRA are not necessarily the same.

Granger causality tests in a panel framework are conducted by estimating separate regressions of changes in the IV and sovereign ratings, as follows:

$$
\Delta I V_{i, t}=\alpha_{1}+\sum_{j=1}^{k} \beta_{1}^{j} * \Delta C C R_{i, t-j}+\sum_{j=1}^{k} \beta_{2}^{j} * \Delta I V_{i, t-j}+\sum_{j=1}^{k} \varphi^{j} * \Delta Z_{i, t-j}+u_{i, t}
$$

\footnotetext{
${ }^{13}$ Equivalent estimations based on the full sample produce qualitatively similar results (available upon request).
} 


$$
\Delta C C R_{i, t}=\alpha_{2}+\sum_{j=1}^{k} \gamma_{1}^{j} * \Delta C C R_{i, t-j}+\sum_{j=1}^{k} \gamma_{2}^{j} * \Delta I V_{i, t-j}+\sum_{j=1}^{k} \theta^{j} * \Delta Z_{i, t-j}+v_{i, t}
$$

$\Delta \mathrm{IV}_{\mathrm{i}, \mathrm{t}}$ denotes daily changes in IV. Consistent with prior literature (e.g. Konstantinidi et al., 2008), we find that $\Delta \mathrm{IV}$ is stationary. We employ Augmented Dickey-Fuller, KSS (Kapetanios et al., 2003) and KPSS (Kwiatkowski, et al., 1992) tests for stationarity in the context of individual time series. In addition, existence of a unit-root in the context of panel data is tested using procedures proposed in Im et al. (2003). The results (available upon request) from all the tests are in line with each other and strongly support the view that $\Delta \mathrm{IV}$ is globally stationary.

$\triangle \mathrm{CCR}$ denotes daily changes in the comprehensive credit rating from a given CRA (note that there are limited numbers of rating events during the 12-year sample period). We use $\triangle \mathrm{CCR}$ instead of $\triangle \mathrm{LCCR}$ to avoid any possible bias in the lead-lag relationship in the middle of the CCR scale (see Afonso et al., 2012), but we provide further evidence on this in Section 5.3. We are interested in the question of whether there are significant market movements prior to rating news or not.

$\mathrm{Z}$ is a vector of fundamentals that affect ratings and implied volatility. However, given the fact that daily observations are not available for all the fundamentals, we restrict $\Delta \mathrm{Z}$ to contain stock market returns ${ }^{14}$ (daily $\log$ returns of the underlying indices) and changes in CCR from the other two CRAs. Firstly, it is reasonable to include equity markets in models examining the lead-lag behaviour between the option market and credit rating signals due to the fact that the equity market and the option market both play roles in the price discovery process (e.g. Chen et al., 2005). Given the well-known leverage effect, the stock index return helps control for the fact that credit ratings and the option market do not adjust at the same frequency. Secondly, including lagged values of ratings from other CRAs controls for the fact

\footnotetext{
14 The stock market returns are stationary during the sample period.
} 
that both the market participants and CRAs are aware of previous ratings from other CRAs. Market participants usually consult with multiple ratings (e.g. Cantor et al., 2007; Bongaerts et al., 2012). There is also evidence of interdependence between CRAs' sovereign ratings (Alsakka and ap Gwilym, 2010). Therefore, it would be naïve to assume that either the market participants or CRAs are unaware of previous rating actions from other CRAs.

Equations (2) and (3) are estimated by the fixed effects technique rather than the Arellano and Bond (1991) GMM technique due to several reasons. Firstly, there are very large numbers of observations for each country. The bias in estimated coefficients of lagged values of dependent variables should be close to zero. Secondly, GMM relies on asymptotic theory and requires a large number of individuals $(\mathrm{N})$, but $\mathrm{N}=24$ in our sample. Moreover, GMM would imply taking the differences of the differences of ratings, IV, and equity returns which would amplify the noise in the regressions. It should be borne in mind that the frequency of rating changes is much less than those of the market indicators. Taking second differences would lead to two consequences which in turn amplify market noise. Firstly, the gap between the frequencies and variability of rating changes and those of market indicators (i.e. IV and stock returns) would be amplified. Secondly, the leverage effect would be neutralized. In testing the possible causality, we employ log-likelihood tests of the joint significance of all coefficients of lagged values of the changes in CCR in Eq. (2) and the changes in IV in Eq. (3).

\section{Empirical results}

\subsection{Influence of sovereign rating news in the option market}

Table 3 presents the results of the event study. Panel A of Table 3 demonstrates an asymmetric pattern in the market reaction to rating signals. Specifically, there are significant responses to rating downgrades while the market impact of upgrades is muted. These reactions are confirmed by each testing procedure. Within a week following downgrades, the 
IV on average reduces by 2.4 percentage points. This is similar to findings in prior literature on the impact of rating signals in other markets in the sense that upgrades generally do not trigger significant reactions from financial markets (Kaminsky and Schmukler, 2002; Gande and Parsley, 2005; Ferreira and Gama, 2007). However, the reduction in IV in response to downgrades is unexpected. Why does the option market consider an equity market in a recently downgraded country (i.e. a lower creditworthiness), to be less uncertain? One possible justification is that the market anticipates credit problems in advance and rating downgrades might serve as means of confirming the market anticipation (see Beber and Brandt, 2006). However, there is no evidence that upgrades and downgrades are anticipated by the market within the prior week. Rating upgrades (downgrades) might be anticipated further in advance. Increasing the length of time windows could answer the question. However, this approach encounters a rating clustering problem and reduces the number of (clean event) observations, hence, the power of the tests. The later methodology relaxes this constraint.

Results from rating outlook signals are presented in Panel B of Table 3. There is no evidence that positive outlook signals induce market reactions. For the negative outlook signals, the non-parametric tests present significant evidence that the IV on average decreases by 1.3 percentage points within the subsequent week. Again, the IV reduces in response to negative rating news. The reaction is not immediate but within a short period. The evidence supports the previous conjecture about the confirmation effects of rating news.

Panel $\mathrm{C}$ of Table 3 presents results from rating watch signals. The IV significantly increases by 1.6 percentage points at the time of both positive and negative watchlist signals. The response to negative watch news is short-lived while the market seems to overreact to positive watch announcements, i.e. the IV reduces by 2.5 percentage points during the following week. Although outlook and watch are monitoring procedures, watchlist is a much 
stronger statement and CRAs aim at a short-term horizon in resolving the watch status. This contributes to explaining the greater relevance of watch announcements to 30-day IV.

One interesting remark on Table 3 is that only watch announcements trigger immediate market responses. The responses are of the same sign, i.e. IV increases, regardless of the sign of watch announcements. In contrast, downgrades induce positive (but not immediate) market reactions, i.e. IV decreases, implying a confirmation effect of actual rating changes. The results suggest that the information content of rating signals for the option market depends on signal types rather than whether they are positive or negative.

\subsection{Varying responses to CRAs’ signals}

Tables 4 to 6 report the estimated coefficients of Equation (1) examining changes in IV during the time windows around rating signals from each CRA. The variable of interest is ' $\triangle \mathrm{LCCR}$ ', representing the 1-day change in the log-transformation of the CCR scale of sovereign $i$ at event date $t$. It should be noted that 1-unit changes in the CCR cause varying effects on the LCCR depending on the starting level of a sovereign rating. For example, 1notch downgrades on AAA sovereigns cause 1.488-unit decreases while 1-notch downgrades on A or A- sovereigns cause 0.379 -unit decreases in the LCCR. ${ }^{15}$ Negative outlook (watch) signals on AAA sovereigns cause 0.726 -unit (1.165-unit) decreases while equivalent signals on A or A- sovereigns cause much weaker responses in the LCCR.

Table 4 shows that S\&P rating news is influential in the market. The only time window where the coefficient of $\triangle \mathrm{LCCR}$ is significant is $[-1,1]$. This holds except for cases of positive watch announcements. ${ }^{16}$ The absence of significant coefficients during the other time windows implies immediate and short-lived effects of S\&P's rating announcements in the

\footnotetext{
${ }^{15}$ There are downgrades/upgrades without prior outlook or watch signals.

${ }^{16} \mathrm{~S} \& \mathrm{P}$ never put a sovereign issuer on watch for possible upgrade during the sample period. All the positive watch actions in the S\&P sample are confirming actual ratings after being on watch for possible downgrades.
} 
market. Downgrades and upgrades impact the market in opposite manners. In cases of downgrades, the coefficient of $\triangle \mathrm{LCCR}$ is significantly greater than zero implying that S\&P's downgrades trigger an increase in the IV. The magnitude of the increase depends not only on the magnitude of rating downgrades but also the current level of sovereign ratings. The IV, on average, increases by 3.8 percentage points in response to 1-notch downgrades on AAA sovereigns $(1.488 * 0.0258)$. The IV decreases by 3.4 percentage points in response to a 1 notch upgrade of a sovereign to AAA $(1.488 * 0.0227)$.

Negative outlook/watch announcements increase the IV while positive outlooks reduce the market uncertainty relating to rated sovereigns' equity markets. The magnitude of the market reactions to positive outlook news is less than for negative outlook. In response to negative outlook news on an AAA sovereign, the IV increases 1.7 percentage points $\left(0.726^{*} 0.0228\right)$. The reactions to negative watch signals are stronger, whereby the IV increases 2.5 percentage points $(1.165 * 0.0216)$. Coefficients of CCR are generally insignificant, which infers that the current level of creditworthiness does not help to explain the dynamics of IV. In other words, the option market already subsumes current financial, macro-economic fundamentals of the rated sovereigns, which is consistent with the view that the evolution of implied volatility cannot be forecasted (e.g. Konstantinidi et al., 2008; Jiang and Tian, 2012).

Table 5 reports the results of Equation (1) for Moody's news. There are some statistically significant coefficients of $\triangle \mathrm{LCCR}$ during the pre-event windows. However, it is problematic to interpret these as evidence of rating anticipation since the coefficients' signs are not consistent with each other. For example, the IV decreases in advance of downgrades but increases prior to negative outlook/watch announcements. All the coefficients of $\Delta \mathrm{LCCR}$ during the $[-1,1]$ time window are insignificant while those during the $[1,5]$ time window are all significant. The results imply that the market does not react immediately to Moody's 
rating news. The reactions come after Moody's rating news is released, and in an opposite manner to the reactions to S\&P signals. Moody's downgrades trigger a decrease in IV while its upgrades trigger an increase. The IV decreases by 3.7 percentage points in response to 1notch downgrades on AAA sovereigns (1.488*0.0248). However, the IV increases by 9.2 percentage points in response to 1-notch upgrades of sovereigns to AAA $\left(1.488^{*} 0.0615\right)$. Other results are similar to Table 4. Specifically, coefficients of CCR are generally insignificant in explaining changes in IV and strong market reactions are found only during one time window.

Table 6 reports the results of Equation (1) for Fitch. The results show that Fitch's rating news has limited influence in the option markets. There is no significant evidence that Fitch rating signals trigger movements in the IV except for cases of downgrades. Here, the coefficient of $\triangle \mathrm{LCCR}$ during the $[-1,1]$ window is significant and negative implying that Fitch's downgrades induce a decrease in the IV. On average, the IV reduces by 3.3 percentage points in response to 1 -notch downgrades on AAA sovereigns $(1.488 * 0.0222)$. In other words, Fitch's downgrades reduce the market uncertainty. Results for CCR coefficients are very similar to those from Moody's and S\&P.

Table 7 presents results of the Monte Carlo experiments. The results are strongly consistent with those from Tables 4-6. Overall, the market reaction varies across CRAs' signals. There is no significant reaction to Fitch announcements while the reactions to rating signals from S\&P are opposite to those from Moody's. The only coefficient which is statistically significant in Panel A of Table 7 (reporting the market reactions to S\&P signals) is of $\triangle \mathrm{LCCR}$ during the $[-1,1]$ window. This indicates that S\&P's rating actions trigger immediate and short-lived responses from the market. The coefficient is negative meaning that S\&P's upgrades (downgrades), where $\triangle \mathrm{LCCR}$ is positive (negative), significantly reduce (increase) IV during the $[-1,1]$ window. In contrast, the only coefficient which is statistically 
significant in Panel B of Table 7 (for Moody's signals) is of $\triangle$ LCCR during the $[1,5]$ window. The positive sign of the coefficient indicates significant increases (decreases) in IV following Moody's upgrades (downgrades).

In summary, there is significant evidence that sovereign credit rating signals induce reactions in the option market. There is also an asymmetric pattern in the market reactions. However, the asymmetry is not only between negative and positive rating news but also across CRAs. The influence of Fitch rating changes is less significant. This is consistent with Bongaerts et al. (2012) who reveal that Fitch plays a 'tiebreaker' role when there is a split between Moody's and S\&P around the investment-speculative threshold. ${ }^{17}$ All sovereigns in our sample are rated at investment-grade (by Moody's and S\&P), which could explain the limited impact of Fitch upgrades. The results for Fitch downgrades imply that even downgrades from the 'tiebreaker' do matter and reduce the market uncertainty. This leads to a possible argument that additional ratings are likely to reduce market uncertainty. To some extent, this is in line with Beber and Brandt $(2006,2009)$ who reveal that scheduled macroeconomic news always reduces market uncertainty (even when news is more negative than prior expectations). Of course, sovereign rating news is not scheduled. However, because market participants usually consult with multiple CRAs (e.g. Cantor et al., 2007; Bongaerts et al., 2012), it is rational for investors to expect actions from the other CRAs after a downgrade from a 'first mover' CRA.

The results from Moody's downgrades and S\&P upgrades lend support to this argument. In our sample, all Moody's downgrades followed S\&P downgrade(s) on the same sovereign(s) except for downgrades of Hungary in November 2008. ${ }^{18}$ Meanwhile, all

\footnotetext{
${ }^{17}$ Bongaerts el al. (2012) is based on corporate ratings. Their decision to treat Fitch as the additional rater was based on the market shares. The market shares are similar between corporate and sovereign ratings.

${ }^{18}$ Moody's downgraded Hungary on 07/11/2008 while S\&P downgraded Hungary on 17/11/2008. However, the former action narrowed while the latter action widened the split between the two CRAs. Some S\&P downgrades (on Austria, France, USA) were not followed by Moody's within our sample periods.
} 
Moody's upgrades during the period led S\&P upgrades on the same sovereigns. ${ }^{19}$ This supports the view that S\&P tends to lead in sovereign downgrades while Moody's tends to be 'first mover' in upgrades (e.g. Alsakka and ap Gwilym, 2010). This section has reported that Moody's downgrades and S\&P upgrades significantly reduce the market uncertainty. It is worth commenting that the reaction to Moody's downgrades is found to be significant only during the $[1,5]$ window not the $[-1,1]$ time window. Moreover, the positive reaction is found after Moody's negative news i.e. downgrades. This reaffirms the implication about the confirmation effects of actual rating actions, which was mentioned in Section 5.1. Actual rating changes (even downgrades) from CRAs who often lag in a specific type of rating action are likely to reduce the market uncertainty.

In order to further clarify the argument, we re-specify our investigations by including dummies indicating whether a rating event widens or narrows the rating split between each pair of the CRAs. However, there is a lack of variation in the dummies indicating the split changes between Moody's and S\&P in each type of rating news, i.e. downgrades, upgrades (as analysed above). Therefore, it is only meaningful to re-specify the investigations on Fitch rating news. As previous results support Bongaerts et al.'s (2012) view that Fitch plays a 'tiebreaker' role, the variable is constructed to consider the split between Fitch actual ratings and average ratings from Moody's and S\&P. The variable takes the value of 1 if Fitch signals reduce the split, -1 if Fitch signals widen the split, and 0 otherwise. The results are qualitatively the same as those in Table 6 (available upon request). The only difference is that the significance level of $\triangle \mathrm{LCCR}$ in explaining $\Delta \mathrm{IV}$ during the $[-1,1]$ window becomes $5 \%$ (instead of $10 \%$ ). The coefficient of the variable is significantly negative at $5 \%$. This result indicates that the market consults with Fitch downgrades in the wider context of Moody's and S\&P ratings. Implied volatility is reduced when Fitch downgrades reduce the disagreement

\footnotetext{
${ }^{19}$ Some sovereigns experienced upgrades from only one of these two CRAs (Czech Republic, Finland, Israel, Korea).
} 
between the CRAs about a sovereign's creditworthiness. This reaffirms the implication about the confirmation effects of actual rating news in Section 5.1.

Overall, these findings support the 'information producing' role of credit ratings both in the context of 'first mover' as well as additional ratings. Taken together, the results stress the importance of credit ratings, especially multiple ratings, because additional ratings are likely to reduce the market uncertainty.

\subsection{Lead-lag relationship between implied volatility and credit ratings}

Table 8 presents the results of Equations (2) and (3). The causality between movements of the option-implied volatility and sovereign rating signals varies across CRAs. There is highly significant evidence of relationships between S\&P and Fitch signals and the option market. In contrast, Moody’s signals exhibit no causality in either direction.

For S\&P, the evidence that changes in IV Granger-cause sovereign rating news is stronger than that of the reverse relationship. $\Delta \mathrm{IV}$ Granger-causes sovereign rating news for each lag length (i.e. within 1 week, 1 month, and 3 months). Meanwhile, S\&P rating news only Granger-causes $\Delta \mathrm{IV}$ for lags within 3 months. The findings are in line with prior papers researching rating anticipation by the CDS market (Norden and Weber, 2004; Afonso et al., 2012) in the sense that rating changes could be anticipated by the derivative market. ${ }^{20}$ The results from Fitch demonstrate stronger implications (than from S\&P) that movements of the IV Granger-cause rating news instead of vice versa. Specifically, there is no significant evidence that Fitch signals Granger-cause $\Delta \mathrm{IV}$ even for lags within 3 months while there is significant evidence that $\Delta \mathrm{IV}$ Granger-causes Fitch rating actions for lags within 1 month and within 3 months. However, we fail to reject the null hypothesis that either $\Delta \mathrm{IV}$ or Fitch

\footnotetext{
${ }^{20} \mathrm{We}$ also estimate probit models testing whether movements in the IV prior to rating events are significant in explaining the probabilities of rating events. The results (available upon request) generally agree that (even) downgrades (from all the CRAs) could be anticipated by the option market.
} 
signals leads each other in the very short-term, i.e. lags within 1 week. In general, the evidence for S\&P and Fitch supports the view that changes in option-implied volatility help explain changes in creditworthiness of underlying entities which is, to some extent, consistent with prior papers (e.g. Collin-Dufresne et al., 2001; Cao et al., 2010). ${ }^{21}$

There is no significant evidence of the causality or lead-lag relationship between $\Delta \mathrm{IV}$ and Moody's actions, even for lags up to 3 months. Among the CRAs, Moody's explicitly provide details on the methodologies of their market implied ratings, e.g. Moody's $\mathrm{KMV}^{\mathrm{TM}}$ which incorporates information from the option market. Therefore, it is hard to argue that Moody's is unaware of the market movements. However, Moody's actions are not following market movements. In other words, Moody's ratings are tardy compared to those from S\&P and Fitch. One logical explanation could be Moody's following a policy of rating stability.

In order to further clarify the above argument, we re-estimate Equations (2) and (3) based on information of actual rating changes and outlook/watch signals, separately. There is significant evidence that $\Delta \mathrm{IV}$ Granger-causes Moody's actual rating changes for lags up to 3 months, but not vice versa. There is no significant evidence that either $\Delta \mathrm{IV}$ or Moody's outlook/watch signals Granger-cause each other for all lags. There is strongly significant evidence that both $\triangle \mathrm{IV}$ and S\&P outlook/watch signals Granger-cause each other for all lags. There is also strongly significant evidence that $\Delta \mathrm{IV}$ Granger-causes Fitch outlook/watch signals, but not vice versa (results available upon request). The results imply that S\&P and Fitch are likely to focus on rating accuracy while Moody's results are consistent with a greater emphasis on rating stability.

Furthermore, we conduct equivalent causality investigations using $\Delta$ LCCR (instead $\triangle \mathrm{CCR}$ ) in Equations (2) and (3). The results (available upon request) are qualitatively different. Specifically, the null hypothesis that $\Delta \mathrm{IV}$ does not Granger-cause $\Delta$ LCCR cannot

\footnotetext{
${ }^{21}$ Collin-Dufresne et al. (2001) use bond spreads while Cao et al. (2010) use CDS spreads.
} 
be rejected (even at the $10 \%$ significance level). This is true except only for Fitch at lags $\mathrm{k}=$ 66. Movements in the option market Granger-cause rating changes in the linear scale. However, this causality relationship is insignificant when the non-linearity of the rating scale is taken into account (i.e. there is no evidence that stronger movements happen prior to rating news on AAA-rated issuers or those rated near the speculative threshold). This implies that the market is aware of credit issues in advance of rating events, yet the magnitude of the credit issues remains uncertain, especially for issuers at the top and bottom of the investmentgrade spectrum.

\subsection{Discussion of results}

All sovereigns in our sample are rated at the investment-grade (by each CRA) and many of them are categorised as developed economies. Such economies are usually characterised by informational transparency, which contributes to the possibility that the creditworthiness of these sovereigns is likely to be observable by financial market participants. As a result, rating changes are more likely to be led by market indicators, such as IV. The results shed light on the price (credit quality information) discovery process. The causal relationships suggest that the process is not simply one way, but also cannot dismiss the importance of rating news. Credit rating signals (especially from S\&P and Moody's) significantly influence IV.

An interesting question over the informational content of rating news can be raised. If the IV leads rating news, the informational content of the news would be subsumed in the IV. Therefore, there should be no reaction found on and/or after the announcements of the news. Nonetheless, reactions to S\&P and Moody's rating news are found to be significant (Tables 4, 5, and 7). The result implies that a significant part of the informational content of rating signals remains until their announcements, even for those led by the option market. Along 
with the finding that additional ratings are likely to reduce the market uncertainty, the results stress the importance and relevance of sovereign ratings to market sentiment.

In order to check the robustness of our findings against extreme observations, we have also conducted equivalent empirical investigations based on excluding the 315 extreme observations (mentioned in Section 3.2). The results are qualitatively similar. Specifically, the findings of the event study and investigations of varying market responses to individual CRAs' signals do not change. There are only two changes in the lead-lag investigations which do not alter our main findings and conclusions.

\section{Conclusions}

This paper investigates the interaction between the stock index option market and sovereign credit ratings assigned by Moody's, S\&P, and Fitch based on a dataset of 24 countries, which covers all countries with liquid stock index options markets (except for countries without rating actions) during 2000 - 2012. The effects of rating signals are evidenced by an event study, and country-matched random sampling regressions. Robustness of the results is confirmed by non-parametric tests and Monte Carlo experiments. Grangercausality tests are employed in order to detect any lead-lag relationships between rating actions and market movements.

A unique contribution to the literature is made by (i) identifying differing influences of CRAs on market uncertainty; (ii) demonstrating the important role of additional sovereign ratings in reducing market uncertainty; (iii) providing evidence of a two-way relationship between sovereign ratings and the equity index option market.

We find an asymmetric pattern in market responses not only between positive and negative events but also varying across CRAs. The market is more likely to react to news from S\&P and Moody's rather than from Fitch, consistent with Bongaerts et al. (2012) who 
argue that Fitch plays a 'tiebreaker' role, at least in corporate ratings. Moreover, Fitch downgrades trigger a decrease in IV, implying that even downgrades from the 'tiebreaker' do matter and reduce the market uncertainty. Furthermore, the market reactions to Moody's and S\&P signals reinforce the analysis that additional signals (both negative and positive) are still informative and reduce the market uncertainty. These stress the importance of multiple ratings and support the information production role of credit ratings in the context of both first-mover as well as subsequent rating news. The results are robust across methodological frameworks and specifications. In addition, we find significant causal relationships between market movements and all types of rating actions assigned by S\&P and Fitch, but only actual rating changes from Moody's. The finding indicates differences in the CRAs' timeliness and policies. S\&P and Fitch credit signals reveal a relatively stronger focus on rating accuracy while Moody's emphasises rating stability. The finding also implies that market participants observe credit issues and react more quickly than CRAs.

From these findings, it is not persuasive to argue that credit rating actions precipitated the European sovereign debt crisis, as was repeatedly suggested by some commentators. By the time of announcements, (even negative) rating actions can serve as a means of confirming the market anticipation and reducing market uncertainty. Some potential policy implications can be raised. The findings support the view of not "shooting the messengers" as expressed by the Association of British Insurers (House of Lords, 2011). In response to the recent crises, credit ratings have been under consideration for removal from regulations as well as investment guidelines. There are clearly benefits of reducing reliance on credit ratings, but proposals such as SEC $(2011 \mathrm{a}, \mathrm{b})$ deserve a caveat, particularly in the context of traditional debt ratings. A strong degree of heterogeneity exists in market responses to rating news, differing by signal, direction and CRA. 


\section{References}

Acharya, V. V. \& Johnson, T. C. (2007). Insider trading in credit derivatives. Journal of Financial Economics, 84, 110-141.

Acharya, V. V., Drechsler, I. \& Schnabl, P. (2014). A pyrrhic victory? Bank bailout and sovereign credit risk. Journal of Finance, forthcoming.

Afonso, A., Furceri, D. \& Gomes, P. (2012). Sovereign credit ratings and financial markets linkages. Journal of International Money and Finance, 31, 606-638.

Alsakka, R. \& ap Gwilym, O. (2010). Leads and lags in sovereign credit ratings. Journal of Banking and Finance, 34, 2614-2626.

Alsakka, R. \& ap Gwilym, O. (2013). Rating agencies' signals during the European sovereign debt crisis: Market impact and spillovers. Journal of Economic Behavior and Organization, 85, 144-162.

Arellano, C. (2008). Default risk and income fluctuations in emerging economies. American Economic Review, 98, 690-712.

Arellano, M. \& Bond, S. (1991). Some tests of specification for panel data: Monte Carlo evidence and an application to employment equations. Review of Economic Studies, 58, 277297.

Arezki, R., Candelon, B. \& Sy, A. N. (2011). Sovereign rating news and financial markets spillovers: Evidence from the European debt crisis. International Monetary Fund working paper No. 11/68.

Avino, D., Lazar, E., \& Varotto, S. (2013). Price discovery of credit spreads in tranquil and crisis periods. International Review of Financial Analysis, 30, 242-253.

Bank of England (2011). Whither the credit ratings industry? Financial Stability Paper No.9. 
Bank for International Settlements (2012). Annual derivatives statistics. Available at: http:/www.bis.org/statistics/derstats.htm.

Basel Committee on Banking Supervision (2011). Basel III: A global regulatory framework for more resilient banks and banking systems (revised June 2011).

Beber, A. \& Brandt, M. (2006). The effect of macroeconomic news on beliefs and preferences: Evidence from the options market. Journal of Monetary Economics, 53, 19972039.

Beber, A. \& Brandt, M. (2009). Resolving macroeconomic uncertainty in stock and bond markets. Review of Finance, 13, 1-45.

Bedendo, M. \& Colla, P. (2013). Sovereign and corporate credit risk: Spillover effects in the Eurozone. CEPR working paper.

Blanco, R., Brennan, S. \& Marsh, I. W. (2005). An empirical analysis of the dynamic relation between investment-grade bonds and credit default swaps. Journal of Finance, 40, $2255-2281$.

Bongaerts, D., Cremers, K. J. \& Goetzmann, W. N. (2012). Tiebreaker: Certification and multiple credit ratings. Journal of Finance, 67, 113-152.

Borensztein, E., Cowan, K. \& Valenzuela, P. (2013). Sovereign ceilings "lite"? The impact of sovereign ratings on corporate ratings. Journal of Banking and Finance, 37, 40144024.

Campbell, J. Y., \& Taksler, G. B. (2003). Equity volatility and corporate bond yields. Journal of Finance, 58, 2321-2349.

Cantor, R., ap Gwilym, O. \& Thomas, S. (2007). The use of credit ratings in investment management in the U.S. and Europe. Journal of Fixed Income, 17, 13-26.

Cao, C., Yu, F. \& Zhong, Z. (2010). The information content of option-implied volatility for credit default swap valuation. Journal of Financial Markets, 13, 321-343. 
Chakravarty, S., Gulen, H. \& Mayhew, S. (2004). Informed trading in stock and option markets. Journal of Finance, 59, 1235-1257.

Chen, C. R., Lung, P. P. \& Tay, N. S. (2005). Information flow between the stock and option markets: Where do informed traders trade? Review of Financial Studies, 14, 1-23.

Coffee, J.C. (2006). Gatekeepers: The professions and corporate governance. Oxford University Press, Oxford, UK.

Collin-Dufresne, P., Goldstein, R. S. \& Martin, J. S. (2001). The determinants of credit spread changes. Journal of Finance, 56, 2177-2207.

Committee on the Global Financial System (2011). The impact of sovereign credit risk on bank funding conditions. Bank for International Settlements CGFS paper No.43.

Ferreira, M. A. \& Gama, P. M. (2007). Does sovereign debt ratings news spill over to international stock markets? Journal of Banking and Finance, 31, 3162-3182.

Gande, A. \& Parsley, D. C. (2005). News spillovers in the sovereign debt market. Journal of Financial Economics, 75, 691-734.

Gennaioli, N., Martin, A. \& Rossi, S. (2014). Sovereign default, domestic banks, and financial institutions. Journal of Finance, 69, 819-866.

House of Lords (2011). Sovereign credit ratings: Shooting the messenger? European Union Committee, 21st Report of Session 2010-2012, HL Paper 189. London, UK.

Im, K. S., Pesaran, M. H., \& Shin, Y. (2003). Testing for unit roots in heterogeneous panels. Journal of Econometrics, 115, 53-74.

International Monetary Fund (2010). Chapter 3: The uses and abuses of sovereign credit ratings. Global Stability Report.

Jiang, G. J. \& Tian, Y. S. (2012). A random walk down the options market. Journal of Futures Markets, 32, 505-535. 
Jin, W., Livnat, J. \& Zhang, Y. (2012). Option prices leading equity prices: Do option traders have an informational advantage? Journal of Accounting Research, 50, 401-432.

Kaminsky, G. \& Schmukler, S. L. (2002). Emerging market instability: Do sovereign ratings affect country risk and stock returns? World Bank Economic Review, 16, 171-195.

Kapetanios, G., Shin, Y., \& Snell, A. (2003). Testing for a unit root in the nonlinear STAR framework. Journal of Econometrics, 112, 359 -379.

Konstantinidi, E., Skiadopoulos, G. \& Tzagkaraki, E. (2008). Can the evolution of implied volatility be forecasted? Evidence from European and US implied volatility indices. Journal of Banking and Finance, 32, 2401-2411.

Kwiatkowski, D., Phillips, P. C. B., Schmidt, P., \& Shin, Y. (1992). Testing the null hypothesis of stationarity against the alternative of a unit root: How sure are we that economic time series have a unit root? Journal of Econometrics, 54, 159-178.

Norden, L. \& Weber, M. (2004). Informational efficiency of credit default swap and stock markets: The impact of credit rating announcements. Journal of Banking and Finance, 28, $2813-2843$.

Prati, A., Schindler, M. \& Valenzuela, P. (2012). Who benefits from capital account liberalization? Evidence from firm-level credit ratings data. Journal of International Money and Finance, 31, 1649-1673.

US Securites and Exchange Commission (2011a). References to credit ratings in certain Investment Company Act rules and forms.

US Securities and Exchange Commission (2011b). Removal of certain references to credit ratings under the Securities Exchange Act of 1934.

White, L. J. (2010). Market: The credit rating agencies. Journal of Economic Perspectives, 24, 211-226. 
Table 1

List of sample countries

\begin{tabular}{|c|c|c|c|}
\hline Country & Period & Country & Period \\
\hline Australia & 2010-2012 & Israel & 2010-2012 \\
\hline Austria & $2000-2012$ & Italy & $2007-2012$ \\
\hline Belgium & 2010-2012 & Japan & 2007-2012 \\
\hline Brazil & 2011-2012 & Korea & 2009-2012 \\
\hline China & $2007-2012$ & Netherlands & $2000-2012$ \\
\hline Czech Republic & 2002-2009 & Poland & $2000-2002$ \\
\hline Finland & 2001-2012 & Russia & 2008-2012 \\
\hline France & 2001-2012 & South Africa & 2011-2012 \\
\hline Germany & $2000-2012$ & Spain & $2007-2012$ \\
\hline Hong Kong & $2007-2012$ & Taiwan & 2010-2012 \\
\hline Hungary & 2002-2009 & UK & 2001-2012 \\
\hline India & 2010-2012 & US & 2002-2012 \\
\hline
\end{tabular}

The data set covers 24 countries. The availability of traded stock index options determines the sample size and sample periods, i.e. we include all countries during the periods that their stock index options are traded (except for Canada, Malaysia, Norway, Sweden, Switzerland who have not experienced any rating actions during the sample periods and Greece whose stock index option market is very small). 
Table 2

Rating events

\begin{tabular}{|c|c|c|c|c|c|c|c|c|c|c|c|c|}
\hline No. of events & \multicolumn{3}{|c|}{ S\&P } & \multicolumn{3}{|c|}{ Moody's } & \multicolumn{3}{|c|}{ Fitch } & \multicolumn{3}{|c|}{ Total } \\
\hline Column number & (1) & (2) & (3) & (4) & (5) & (6) & (7) & (8) & (9) & (10) & (11) & (12) \\
\hline Actual rating & 9 & 16 & 25 & 7 & 12 & 19 & 7 & 9 & 16 & 23 & 37 & 60 \\
\hline Outlook & 13 & 29 & 42 & 10 & 16 & 26 & 9 & 19 & 28 & 32 & 64 & 96 \\
\hline Total & 33 & 56 & 89 & 26 & 39 & 65 & 19 & 31 & 50 & 78 & 126 & 204 \\
\hline
\end{tabular}

This table reports numbers of rating events released by the CRAs during the sample periods. Columns (1), (2), (3) report numbers of positive, negative, and total rating signals from S\&P, respectively. Similarly, columns (4) to (9) report corresponding numbers from Moody's and Fitch. (10) = (1) $+(4)+(7) ;(11)=$ $(2)+(5)+(8) ;(12)=(3)+(6)+(9)$. 
Table 3

Results of the event study

\begin{tabular}{|c|c|c|c|}
\hline Time window & {$[-5,-1]$} & {$[-1,1]$} & {$[1,5]$} \\
\hline \multicolumn{4}{|c|}{ Panel A: Actual rating changes } \\
\hline & \multicolumn{3}{|c|}{ Downgrade } \\
\hline$\Delta \overline{I V}(\%)$ & -1.044 & 1.023 & $-2.434 *$ \\
\hline p-val. of t-test & 0.215 & 0.220 & 0.066 \\
\hline p-val. of sign test & 0.247 & 0.557 & 0.009 \\
\hline \multirow{2}{*}{$\begin{array}{l}\text { p-val. of Wilcoxon test } \\
\text { No. of Events }\end{array}$} & 0.163 & 0.174 & 0.029 \\
\hline & \multicolumn{3}{|c|}{27} \\
\hline
\end{tabular}

\begin{tabular}{|c|c|c|}
\hline \multicolumn{3}{|c|}{ Upgrade } \\
\hline-2.659 & 0.880 & 0.854 \\
\hline 0.238 & 0.425 & 0.685 \\
\hline 0.607 & 0.607 & 1.000 \\
\hline 0.543 & 0.570 & 0.903 \\
\hline
\end{tabular}

Panel B: Outlook signals

\begin{tabular}{|l|r|r|r|}
\cline { 2 - 4 } \multicolumn{1}{c|}{} & \multicolumn{3}{c|}{ Negative outlook } \\
\hline$\Delta \overline{I V}(\%)$ & -0.719 & 1.383 & $-1.274^{\dagger}$ \\
p-val. of t-test & 0.140 & 0.159 & 0.118 \\
p-val. of sign test & 0.220 & 0.583 & 0.027 \\
p-val. of Wilcoxon test & 0.199 & 0.227 & 0.011 \\
\cline { 2 - 4 } No. of Events & \multicolumn{3}{|c|}{57} \\
\hline
\end{tabular}

\begin{tabular}{|r|r|r|}
\hline \multicolumn{3}{|c|}{ Positive outlook } \\
\hline-0.955 & 0.618 & -0.312 \\
0.153 & 0.368 & 0.566 \\
0.327 & 0.845 & 1.000 \\
0.214 & 0.380 & 0.544 \\
\hline \multicolumn{3}{|c|}{29} \\
\hline
\end{tabular}

Panel C: Watch signals

\begin{tabular}{|l|r|r|r|}
\cline { 2 - 4 } \multicolumn{1}{c|}{} & \multicolumn{3}{c|}{ Negative watch } \\
\hline$\Delta \overline{I V}(\%)$ & -0.243 & $\mathbf{1 . 5 5 1 *}$ & -0.382 \\
p-val. of t-test & 0.760 & 0.067 & 0.706 \\
p-val. of sign test & 0.541 & 0.064 & 0.838 \\
p-val. of Wilcoxon test & 0.931 & 0.029 & 0.909 \\
\cline { 2 - 4 } No. of Events & \multicolumn{3}{|c|}{24} \\
\hline
\end{tabular}

\begin{tabular}{|r|r|r|}
\hline \multicolumn{3}{|c|}{ Positive watch } \\
\hline-0.028 & $\mathbf{1 . 5 6 7 *}$ & $\mathbf{- 2 . 4 6 9 * *}$ \\
0.963 & 0.051 & 0.017 \\
0.523 & 0.286 & 0.000 \\
0.592 & 0.040 & 0.003 \\
\hline \multicolumn{3}{|c|}{22} \\
\hline
\end{tabular}

Only 'clean' events from all CRAs are used. $\Delta \overline{I V}$ reports mean value of changes in the IV during the time windows in percentage points. Cases in bold denote significance at least at $10 \%$ level in both 2sided t-test and either of 2 -sided non-parametric tests. ${ }^{*}, * *$ denotes significant in t-test at $10 \%, 5 \%$ level of significance. ${ }^{\dagger}$ denotes significant in the non-parametric tests and not in the t-test. See Tables 1 and 2 for details on the data sample. The reason for mis-matches in no. of events compared to columns 10 and 11 of Table 2 is the absence of unclean events. 
Table 4

Estimation results of Eq. (1) for the S\&P events

\begin{tabular}{|c|c|c|c|c|c|c|c|c|c|c|c|c|c|c|}
\hline Time window & {$[-66,-22]$} & {$[-22,-5]$} & {$[-5,-1]$} & {$[-1,1]$} & {$[1,5]$} & {$[5,22]$} & {$[22,66]$} & {$[-66,-22]$} & {$[-22,-5]$} & {$[-5,-1]$} & {$[-1,1]$} & {$[1,5]$} & {$[5,22]$} & {$[22,66]$} \\
\hline Panel A & \multicolumn{7}{|c|}{ Downgrade } & \multicolumn{7}{|c|}{ Upgrade } \\
\hline \multirow[t]{2}{*}{$\Delta \mathrm{LCCR}$} & 0.0083 & -0.0111 & -0.0094 & $0.0258^{* *}$ & -0.0006 & -0.0070 & 0.0074 & 0.0766 & -0.0215 & 0.0108 & $-0.0227^{* *}$ & -0.0176 & 0.0050 & 0.0184 \\
\hline & $(0.815)$ & $(0.620)$ & $(0.374)$ & $(0.035)$ & $(0.968)$ & $(0.758)$ & $(0.745)$ & $(0.405)$ & $(0.594)$ & $(0.383)$ & $(0.043)$ & $(0.104)$ & $(0.844)$ & $(0.912)$ \\
\hline \multirow[t]{2}{*}{ CCR } & -0.0073 & -0.0016 & 0.0014 & 0.0014 & 0.0018 & 0.0068 & 0.0007 & -0.0062 & 0.0009 & 0.0013 & 0.00123 & 0.0013 & 0.0077* & -0.0030 \\
\hline & $(0.109)$ & $(0.634)$ & $(0.591)$ & $(0.252)$ & $(0.258)$ & $(0.110)$ & $(0.883)$ & $(0.287)$ & $(0.806)$ & $(0.717)$ & $(0.378)$ & $(0.418)$ & $(0.096)$ & $(0.580)$ \\
\hline Year/ Country & Yes & Yes & Yes & Yes & Yes & Yes & Yes & Yes & Yes & Yes & Yes & Yes & Yes & Yes \\
\hline Adj. $R^{2}$ & $23.80 \%$ & $45.43 \%$ & $7.65 \%$ & $7.99 \%$ & $10.93 \%$ & $35.44 \%$ & $0.78 \%$ & $20.86 \%$ & $44.81 \%$ & $7.04 \%$ & $8.96 \%$ & $11.97 \%$ & $35.47 \%$ & $1.03 \%$ \\
\hline Panel B & \multicolumn{7}{|c|}{ Negative outlook } & \multicolumn{7}{|c|}{ Positive outlook } \\
\hline \multirow[t]{2}{*}{$\Delta \mathrm{LCCR}$} & -0.05849 & 0.0216 & -0.0103 & $0.0228^{*}$ & 0.0063 & 0.0055 & -0.0483 & -0.0096 & 0.0003 & 0.0081 & $-0.0161^{*}$ & -0.0046 & 0.0002 & 0.0068 \\
\hline & $(0.434)$ & $(0.558)$ & $(0.310)$ & $(0.056)$ & $(0.672)$ & $(0.828)$ & $(0.701)$ & $(0.790)$ & $(0.990)$ & $(0.444)$ & $(0.096)$ & $(0.785)$ & $(0.995)$ & $(0.796)$ \\
\hline \multirow[t]{2}{*}{ CCR } & $-0.0081^{*}$ & -0.0003 & 0.0010 & 0.0019 & 0.0017 & 0.0066 & -0.0024 & $-0.0088^{*}$ & -0.0020 & 0.0019 & 0.00113 & 0.0019 & 0.0066 & 0.0001 \\
\hline & $(0.087)$ & $(0.931)$ & $(0.745)$ & $(0.120)$ & $(0.292)$ & $(0.155)$ & $(0.664)$ & $(0.096)$ & $(0.591)$ & $(0.550)$ & $(0.312)$ & $(0.274)$ & $(0.167)$ & $(0.979)$ \\
\hline Year/ Country & Yes & Yes & Yes & Yes & Yes & Yes & Yes & Yes & Yes & Yes & Yes & Yes & Yes & Yes \\
\hline Adj. $\mathrm{R}^{2}$ & $21.04 \%$ & $44.69 \%$ & $7.71 \%$ & $8.67 \%$ & $9.39 \%$ & $18.55 \%$ & $0.95 \%$ & $24.05 \%$ & $45.47 \%$ & $7.96 \%$ & $13.09 \%$ & $12.58 \%$ & $40.33 \%$ & $0.71 \%$ \\
\hline Panel C & \multicolumn{7}{|c|}{ Negative watch } & \multicolumn{7}{|c|}{ Positive watch } \\
\hline \multirow[t]{2}{*}{$\Delta \mathrm{LCCR}$} & -0.07302 & 0.0276 & -0.0194 & $0.0216^{*}$ & 0.0119 & 0.0042 & -0.0381 & 0.0519 & -0.0450 & 0.0022 & -0.0171 & 0.0041 & -0.0287 & 0.0594 \\
\hline & $(0.518)$ & $(0.562)$ & $(0.139)$ & $(0.082)$ & $(0.501)$ & $(0.894)$ & $(0.848)$ & $(0.643)$ & $(0.337)$ & $(0.870)$ & $(0.298)$ & $(0.854)$ & $(0.355)$ & $(0.766)$ \\
\hline \multirow[t]{2}{*}{$\mathrm{CCR}$} & -0.007 & -0.0012 & 0.0017 & 0.0013 & 0.0016 & 0.0068 & -0.0013 & -0.0075 & 0.0007 & 0.0012 & 0.00159 & 0.0013 & 0.0071 & -0.0036 \\
\hline & $(0.153)$ & $(0.746)$ & $(0.589)$ & $(0.268)$ & $(0.336)$ & $(0.147)$ & $(0.829)$ & $(0.146)$ & $(0.866)$ & $(0.674)$ & $(0.213)$ & $(0.406)$ & $(0.123)$ & $(0.584)$ \\
\hline Year/ Country & Yes & Yes & Yes & Yes & Yes & Yes & Yes & Yes & Yes & Yes & Yes & Yes & Yes & Yes \\
\hline Adj. $R^{2}$ & $21.05 \%$ & $44.75 \%$ & $7.50 \%$ & $8.70 \%$ & $9.82 \%$ & $34.30 \%$ & $1.02 \%$ & $21.07 \%$ & $44.95 \%$ & $7.21 \%$ & $7.54 \%$ & $10.08 \%$ & $33.68 \%$ & $1.05 \%$ \\
\hline
\end{tabular}

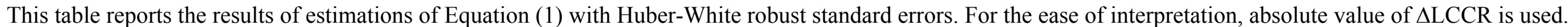

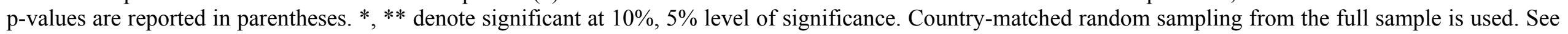
Tables 1 and 2 for details on the data sample. 
Table 5

Estimation results of Eq. (1) for the Moody's events

\begin{tabular}{|c|c|c|c|c|c|c|c|c|c|c|c|c|c|c|}
\hline Time window & {$[-66,-22]$} & {$[-22,-5]$} & {$[-5,-1]$} & {$[-1,1]$} & {$[1,5]$} & {$[5,22]$} & {$[22,66]$} & {$[-66,-22]$} & {$[-22,-5]$} & {$[-5,-1]$} & {$[-1,1]$} & {$[1,5]$} & {$[5,22]$} & {$[22,66]$} \\
\hline Panel A & \multicolumn{7}{|c|}{ Downgrade } & \multicolumn{7}{|c|}{ Upgrade } \\
\hline \multirow{2}{*}{$\triangle \mathrm{LCCR}$} & 0.0448 & $-0.0327^{* *}$ & 0.0195 & 0.0019 & $-0.0248^{* *}$ & 0.0101 & 0.0014 & -0.9433 & 0.4813 & $-0.0707^{* *}$ & 0.0106 & $0.0615^{* *}$ & -0.0118 & 0.0112 \\
\hline & $(0.105)$ & $(0.026)$ & $(0.131)$ & $(0.859)$ & $(0.037)$ & $(0.620)$ & $(0.945)$ & $(0.178)$ & $(0.119)$ & $(0.035)$ & $(0.333)$ & $(0.016)$ & $(0.761)$ & $(0.762)$ \\
\hline \multirow[t]{2}{*}{$\mathrm{CCR}$} & -0.0015 & -0.0021 & 0.0005 & 0.0006 & 0.0016 & 0.0029 & 0.0011 & -0.0316 & 0.0122 & -0.0005 & 0.0006 & $0.0024^{*}$ & 0.0028 & -0.0003 \\
\hline & $(0.607)$ & $(0.298)$ & $(0.702)$ & $(0.426)$ & $(0.102)$ & $(0.299)$ & $(0.767)$ & $(0.140)$ & $(0.205)$ & $(0.756)$ & $(0.478)$ & $(0.053)$ & $(0.374)$ & $(0.930)$ \\
\hline Year/ Country & Yes & Yes & Yes & Yes & Yes & Yes & Yes & Yes & Yes & Yes & Yes & Yes & Yes & Yes \\
\hline Adj. $\mathrm{R}^{2}$ & $34.72 \%$ & $25.84 \%$ & $6.86 \%$ & $7.16 \%$ & $7.61 \%$ & $33.21 \%$ & $1.02 \%$ & $28.58 \%$ & $49.56 \%$ & $8.29 \%$ & $7.02 \%$ & $12.97 \%$ & $32.98 \%$ & $1.02 \%$ \\
\hline Panel B & \multicolumn{7}{|c|}{ Negative outlook } & \multicolumn{7}{|c|}{ Positive outlook } \\
\hline \multirow[t]{2}{*}{$\Delta \mathrm{LCCR}$} & 0.4498 & -0.2165 & $0.0372^{*}$ & 0.0029 & $-0.0371^{* *}$ & 0.0118 & -0.0078 & -0.5782 & 0.2853 & -0.0393 & -0.0144 & $0.0412^{* *}$ & -0.0110 & -0.0182 \\
\hline & $(0.194)$ & $(0.156)$ & $(0.078)$ & $(0.771)$ & $(0.023)$ & $(0.548)$ & $(0.742)$ & $(0.235)$ & $(0.190)$ & $(0.168)$ & $(0.116)$ & $(0.047)$ & $(0.669)$ & $(0.459)$ \\
\hline \multirow[t]{2}{*}{$\mathrm{CCR}$} & -0.0186 & 0.0061 & $-2.2 \mathrm{E}-05$ & 0.0007 & $0.0018^{*}$ & 0.0027 & 0.0009 & -0.0207 & 0.0082 & -0.0005 & 0.0007 & 0.0019* & 0.0033 & -0.0007 \\
\hline & $(0.210)$ & $(0.351)$ & $(0.986)$ & $(0.373)$ & $(0.086)$ & $(0.318)$ & $(0.794)$ & $(0.216)$ & $(0.279)$ & $(0.715)$ & $(0.418)$ & $(0.085)$ & $(0.262)$ & $(0.856)$ \\
\hline Year/ Country & Yes & Yes & Yes & Yes & Yes & Yes & Yes & Yes & Yes & Yes & Yes & Yes & Yes & Yes \\
\hline Adj. $R^{2}$ & $24.85 \%$ & $46.93 \%$ & $7.79 \%$ & $7.06 \%$ & $12.52 \%$ & $33.33 \%$ & $1.03 \%$ & $25.46 \%$ & $47.73 \%$ & $7.84 \%$ & $7.46 \%$ & $12.93 \%$ & $33.51 \%$ & $1.05 \%$ \\
\hline Panel C & \multicolumn{7}{|c|}{ Negative watch } & \multicolumn{7}{|c|}{ Positive watch } \\
\hline$\triangle \mathrm{LCCR}$ & 0.5181 & -0.2685 & $0.0439^{*}$ & 0.0041 & $-0.0328^{*}$ & 0.0041 & 0.0137 & -0.5241 & 0.2622 & -0.0304 & -0.0045 & $0.0285^{*}$ & 0.0053 & 0.0027 \\
\hline \multirow{3}{*}{$\mathrm{CCR}$} & $(0.216)$ & $(0.160)$ & $(0.098)$ & $(0.711)$ & $(0.052)$ & $(0.860$ & $(0.570)$ & $(0.242)$ & $(0.194)$ & $(0.209)$ & $(0.694)$ & $(0.093)$ & $(0.726)$ & $(0.932)$ \\
\hline & -0.0214 & 0.0084 & -0.0003 & 0.0006 & $0.0018^{*}$ & 0.0030 & -0.0004 & -0.0159 & 0.0051 & -0.0003 & 0.0007 & $0.0020^{*}$ & 0.7260 & 0.0004 \\
\hline & $(0.202)$ & $(0.264)$ & $(0.846)$ & $(0.490)$ & $(0.098)$ & $(0.295)$ & $(0.918)$ & $(0.217)$ & $(0.382)$ & $(0.811)$ & $(0.367)$ & $(0.051)$ & $(0.346)$ & $(0.923)$ \\
\hline Year/ Country & Yes & Yes & Yes & Yes & Yes & Yes & Yes & Yes & Yes & Yes & Yes & Yes & Yes & Yes \\
\hline Adj. $\mathrm{R}^{2}$ & $25.28 \%$ & $47.56 \%$ & $7.84 \%$ & $6.74 \%$ & $11.82 \%$ & $33.01 \%$ & $1.02 \%$ & $24.98 \%$ & $47.13 \%$ & $7.80 \%$ & $6.98 \%$ & $11.82 \%$ & $33.36 \%$ & $1.00 \%$ \\
\hline
\end{tabular}

This table reports the results of estimations of Equation (1) with Huber-White robust standard errors. For the ease of interpretation, absolute value of $\Delta$ LCCR is used. p-values are reported in parentheses. $*, * *$ denote significant at $10 \%, 5 \%$ level of significance. Country-matched random sampling from the full sample is used. See Tables 1 and 2 for details on the data sample. 
Table 6

Estimation results of Eq. (1) for the Fitch events

\begin{tabular}{|c|c|c|c|c|c|c|c|c|c|c|c|c|c|c|}
\hline \multirow[t]{2}{*}{ Time window } & {$[-66,-22]$} & {$[-22,-5]$} & {$[-5,-1]$} & {$[-1,1]$} & {$[1,5]$} & {$[5,22]$} & {$[22,66]$} & {$[-66,-22]$} & {$[-22,-5]$} & {$[-5,-1]$} & {$[-1,1]$} & {$[1,5]$} & {$[5,22]$} & {$[22,66]$} \\
\hline & \multicolumn{7}{|c|}{ Downgrade } & \multicolumn{7}{|c|}{ Upgrade } \\
\hline \multirow[t]{2}{*}{$\Delta \mathrm{LCCR}$} & 0.0462 & 0.0425 & -0.0124 & $-0.0222^{*}$ & -0.0108 & -0.0107 & -0.0254 & 0.0056 & 0.0275 & -0.0282 & 0.0050 & 0.0056 & -0.0604 & 0.0101 \\
\hline & $(0.206)$ & $(0.341)$ & $(0.636)$ & $(0.062)$ & $(0.636)$ & $(0.607)$ & $(0.389)$ & $(0.886)$ & $(0.498)$ & $(0.267)$ & $(0.780)$ & $(0.705)$ & $(0.346)$ & $(0.877)$ \\
\hline \multirow[t]{2}{*}{$\mathrm{CCR}$} & 0.0008 & -0.0011 & -0.0006 & 0.0014 & 0.0007 & $0.0061^{*}$ & -0.0007 & 0.0014 & -0.0023 & -0.0003 & 0.0019 & 0.0003 & $0.0071^{*}$ & 0.0003 \\
\hline & $(0.825)$ & $(0.701)$ & $(0.796)$ & $(0.313)$ & $(0.655)$ & $(0.068)$ & $(0.895)$ & $(0.721)$ & $(0.450)$ & $(0.903)$ & $(0.206)$ & $(0.883)$ & $(0.066)$ & $(0.962)$ \\
\hline Year/ Country & Yes & Yes & Yes & Yes & Yes & Yes & Yes & Yes & Yes & Yes & Yes & Yes & Yes & Yes \\
\hline \multirow[t]{2}{*}{ Adj. $R^{2}$} & $20.92 \%$ & $44.68 \%$ & $7.34 \%$ & $7.18 \%$ & $9.66 \%$ & $40.84 \%$ & $0.78 \%$ & $20.91 \%$ & $44.70 \%$ & $7.27 \%$ & $7.49 \%$ & $9.33 \%$ & $33.89 \%$ & $1.01 \%$ \\
\hline & \multicolumn{7}{|c|}{ Negative outlook } & \multicolumn{7}{|c|}{ Positive outlook } \\
\hline \multirow[t]{2}{*}{$\triangle \mathrm{LCCR}$} & $0.0475^{*}$ & 0.0190 & -0.0105 & -0.0109 & -0.0056 & 0.0243 & -0.0480 & $-0.0694^{* *}$ & -0.0425 & 0.0027 & 0.0119 & 0.0002 & -0.0174 & 0.0176 \\
\hline & $(0.099)$ & $(0.664)$ & $(0.657)$ & $(0.422)$ & $(0.764)$ & $(0.515)$ & $(0.164)$ & $(0.032)$ & $(0.373)$ & $(0.934)$ & $(0.413)$ & $(0.994)$ & $(0.546)$ & $(0.575)$ \\
\hline \multirow[t]{2}{*}{ CCR } & -0.0005 & -0.0015 & -0.0003 & 0.0009 & 0.0005 & $0.0071^{* *}$ & -0.0033 & 0.0018 & 0.0001 & -0.0007 & 0.0020 & 0.0004 & $0.0071^{*}$ & 0.0001 \\
\hline & $(0.884)$ & $(0.621)$ & $(0.885)$ & $(0.482)$ & $(0.770)$ & $(0.052)$ & $(0.526)$ & $(0.644)$ & $(0.963)$ & $(0.787)$ & $(0.194)$ & $(0.815)$ & $(0.068)$ & $(0.986)$ \\
\hline Year/ Country & Yes & Yes & Yes & Yes & Yes & Yes & Yes & Yes & Yes & Yes & Yes & Yes & Yes & Yes \\
\hline \multirow[t]{2}{*}{ Adj. $R^{2}$} & $20.97 \%$ & $44.67 \%$ & $7.81 \%$ & $7.27 \%$ & $9.46 \%$ & $33.69 \%$ & $1.03 \%$ & $20.88 \%$ & $44.99 \%$ & $7.49 \%$ & $7.74 \%$ & $9.10 \%$ & $42.31 \%$ & $0.82 \%$ \\
\hline & \multicolumn{7}{|c|}{ Negative watch } & \multicolumn{7}{|c|}{ Positive watch } \\
\hline \multirow[t]{2}{*}{$\Delta \mathrm{LCCR}$} & 0.0478 & 0.0298 & 0.0007 & -0.0188 & -0.0036 & 0.0244 & -0.0353 & $-0.0469^{*}$ & -0.0238 & 0.0030 & 0.0115 & 0.0054 & -0.0259 & 0.0389 \\
\hline & $(0.120)$ & $(0.480)$ & $(0.978)$ & $(0.119)$ & $(0.840)$ & $(0.507)$ & $(0.276)$ & $(0.098)$ & $(0.570)$ & $(0.901)$ & $(0.367)$ & $(0.760)$ & $(0.472)$ & $(0.242)$ \\
\hline \multirow[t]{2}{*}{ CCR } & 0.0008 & -0.0017 & -0.0008 & 0.0019 & 0.0007 & $0.0068^{*}$ & -0.0001 & 0.0002 & -0.0014 & -0.0002 & 0.0008 & 0.0005 & $0.0072^{* *}$ & -0.0032 \\
\hline & $(0.829)$ & $(0.592)$ & $(0.732)$ & $(0.182)$ & $(0.665)$ & $(0.072)$ & (0.993) & $(0.959)$ & $(0.648)$ & $(0.906)$ & $(0.535)$ & $(0.745)$ & $(0.048)$ & $(0.547)$ \\
\hline Year/ Country & Yes & Yes & Yes & Yes & Yes & Yes & Yes & Yes & Yes & Yes & Yes & Yes & Yes & Yes \\
\hline Adj. $\mathrm{R}^{2}$ & $20.92 \%$ & $44.65 \%$ & $7.05 \%$ & $7.60 \%$ & $9.34 \%$ & $33.49 \%$ & $1.02 \%$ & $20.93 \%$ & $44.66 \%$ & $7.04 \%$ & $7.28 \%$ & $9.53 \%$ & $33.57 \%$ & $1.02 \%$ \\
\hline
\end{tabular}

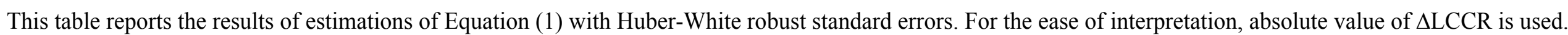

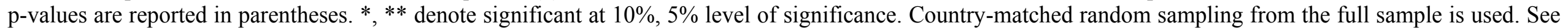
Tables 1 and 2 for details on the data sample. 
Table 7

Results of the Monte Carlo experiment

\begin{tabular}{|c|c|c|c|c|c|c|c|}
\hline Time window & {$[-66,-22]$} & {$[-22,-5]$} & {$[-5,-1]$} & {$[-1,1]$} & {$[1,5]$} & {$[5,22]$} & {$[22,66]$} \\
\hline \multicolumn{8}{|c|}{ Panel A: S\&P rating news } \\
\hline \multirow[t]{2}{*}{$\Delta \mathrm{LCCR}$} & 0.0346 & -0.0282 & 0.0111 & $-0.0202 * *$ & -0.0058 & 0.0121 & 0.0207 \\
\hline & $(0.322)$ & $(-0.443)$ & $(1.092)$ & $(-2.038)$ & $(-0.425)$ & $(0.581)$ & $(0.576)$ \\
\hline Year/Country dummies \& CCR & Yes & Yes & Yes & Yes & Yes & Yes & Yes \\
\hline $\mathrm{R}^{2}$ & $39.78 \%$ & $42.11 \%$ & $19.02 \%$ & $12.62 \%$ & $16.57 \%$ & $30.53 \%$ & $36.39 \%$ \\
\hline $\mathrm{N}$ & 253 & 256 & 262 & 262 & 259 & 256 & 248 \\
\hline No. of estimations & 10,000 & 10,000 & 10,000 & 10,000 & 10,000 & 10,000 & 10,000 \\
\hline \multicolumn{8}{|c|}{ Panel B: Moody's rating news } \\
\hline \multirow[t]{2}{*}{$\triangle \mathrm{LCCR}$} & -0.3203 & 0.1994 & -0.0291 & -0.0042 & $0.0339 * *$ & -0.0088 & 0.0038 \\
\hline & $(-1.329)$ & $(1.381)$ & $(-1.592)$ & $(-0.438)$ & $(1.984)$ & $(-0.418)$ & $(0.167)$ \\
\hline Year/Country dummies \& CCR & Yes & Yes & Yes & Yes & Yes & Yes & Yes \\
\hline $\mathrm{R}^{2}$ & $41.72 \%$ & $43.37 \%$ & $19.67 \%$ & $11.80 \%$ & $18.02 \%$ & $29.86 \%$ & $36.65 \%$ \\
\hline $\mathrm{N}$ & 253 & 256 & 263 & 262 & 259 & 256 & 249 \\
\hline No. of estimations & 10,000 & 10,000 & 10,000 & 10,000 & 10,000 & 10,000 & 10,000 \\
\hline \multicolumn{8}{|c|}{ Panel C: Fitch rating news } \\
\hline \multirow[t]{2}{*}{$\triangle \mathrm{LCCR}$} & -0.0428 & -0.0207 & 0.0128 & 0.0111 & -0.0024 & -0.0196 & 0.0301 \\
\hline & $(-1.219)$ & $(-0.457)$ & $(0.575)$ & $(0.968)$ & $(-0.154)$ & $(-0.568)$ & $(0.880)$ \\
\hline Year/Country dummies \& CCR & Yes & Yes & Yes & Yes & Yes & Yes & Yes \\
\hline $\mathrm{R}^{2}$ & $39.92 \%$ & $41.82 \%$ & $18.73 \%$ & $12.03 \%$ & $16.29 \%$ & $29.94 \%$ & $36.61 \%$ \\
\hline $\mathrm{N}$ & 254 & 256 & 263 & 262 & 259 & 256 & 249 \\
\hline No. of estimations & 10,000 & 10,000 & 10,000 & 10,000 & 10,000 & 10,000 & 10,000 \\
\hline
\end{tabular}

This table reports the averages across all 10,000 estimations of Equation (1) with Huber-White robust standard errors. Each estimation of the equation is based on one independent random country-matched sampling. t-statistics are reported in parentheses. ${ }^{* *}$ denotes significant at $5 \%$. $\mathrm{N}$ reports maximum number of observations for one estimation as this number varies slightly between estimations. The estimated coefficients of CCR are not reported for ease of presentation. Different to Tables 4-6, we do not use absolute value of $\triangle \mathrm{LCCR}$ here. See Tables 1 and 2 for details on the data sample. 


\section{Table 8}

\section{Results of log-likelihood tests of causality between rating actions and implied volatility}

\begin{tabular}{|c|c|c|c|}
\hline & Null hypothesis & & \\
\hline \multirow{4}{*}{$\begin{array}{c}\mathrm{k}=5 \\
\text { i.e. lags } \\
\text { within } 1 \\
\text { week }\end{array}$} & \multirow{2}{*}{$\begin{array}{l}\Delta \mathrm{IV} \text { does not cause } \\
\text { S\&P actions }\end{array}$} & LR-val. & $11.09 * *$ \\
\hline & & p-val. & 0.0495 \\
\hline & \multirow{2}{*}{$\begin{array}{l}\text { S\&P actions do not } \\
\text { cause } \Delta I V\end{array}$} & LR-val. & 7.71 \\
\hline & & p-val. & 0.1730 \\
\hline \multirow{4}{*}{$\begin{array}{c}\mathrm{k}=22 \\
\text { i.e. lags } \\
\text { within } 1 \\
\text { month }\end{array}$} & \multirow{2}{*}{$\begin{array}{l}\Delta \mathrm{IV} \text { does not cause } \\
\text { S\&P actions }\end{array}$} & LR-val. & $50.60 * * *$ \\
\hline & & p-val. & 0.0005 \\
\hline & \multirow{2}{*}{$\begin{array}{l}\text { S\&P actions do not } \\
\text { cause } \Delta \mathrm{IV}\end{array}$} & LR-val. & 30.13 \\
\hline & & p-val. & 0.1153 \\
\hline \multirow{4}{*}{$\begin{array}{c}\mathrm{k}=66 \\
\text { i.e. lags } \\
\text { within } 3 \\
\text { months }\end{array}$} & \multirow{2}{*}{$\begin{array}{l}\Delta \mathrm{IV} \text { does not cause } \\
\mathrm{S} \& \mathrm{P} \text { actions }\end{array}$} & LR-val. & $107.90 * * *$ \\
\hline & & p-val. & 0.0009 \\
\hline & \multirow{2}{*}{$\begin{array}{l}\text { S\&P actions do not } \\
\text { cause } \Delta I V\end{array}$} & LR-val. & $116.17 * * *$ \\
\hline & & p-val. & 0.0001 \\
\hline
\end{tabular}

\begin{tabular}{|c|c|c|}
\hline Null hypothesis & & \\
\hline$\Delta \mathrm{IV}$ does not cause & LR-val. & 3.75 \\
\hline Moody's actions & p-val. & 0.5853 \\
\hline Moody's actions do not & LR-val. & 7.87 \\
\hline cause $\Delta \mathrm{IV}$ & p-val. & 0.1637 \\
\hline$\Delta \mathrm{IV}$ does not cause & LR-val. & 20.02 \\
\hline Moody's actions & p-val. & 0.5818 \\
\hline Moody's actions do not & LR-val. & 10.85 \\
\hline cause $\Delta I V$ & p-val. & 0.9769 \\
\hline$\Delta \mathrm{IV}$ does not cause & LR-val. & 80.46 \\
\hline Moody's actions & p-val. & 0.1087 \\
\hline Moody's actions do not & LR-val. & 45.7 \\
\hline cause $\Delta \mathrm{IV}$ & p-val. & 0.9732 \\
\hline
\end{tabular}

\begin{tabular}{|c|c|c|}
\hline Null hypothesis & & \\
\hline $\begin{array}{l}\Delta \mathrm{IV} \text { does not cause } \\
\text { Fitch actions }\end{array}$ & $\begin{array}{l}\text { LR-val. } \\
\text { p-val. }\end{array}$ & $\begin{array}{r}6.88 \\
0.2299\end{array}$ \\
\hline $\begin{array}{l}\text { Fitch actions do not } \\
\text { cause } \Delta \mathrm{IV}\end{array}$ & $\begin{array}{l}\text { LR-val. } \\
\text { p-val. }\end{array}$ & $\begin{array}{r}4.02 \\
0.5470\end{array}$ \\
\hline $\begin{array}{l}\Delta \mathrm{IV} \text { does not cause } \\
\text { Fitch actions }\end{array}$ & $\begin{array}{l}\text { LR-val. } \\
\text { p-val. }\end{array}$ & $\begin{array}{r}44.73 * * * \\
0.0029\end{array}$ \\
\hline $\begin{array}{l}\text { Fitch actions do not } \\
\text { cause } \Delta \mathrm{IV}\end{array}$ & $\begin{array}{l}\text { LR-val. } \\
\text { p-val. }\end{array}$ & $\begin{array}{r}11.02 \\
0.9744 \\
\end{array}$ \\
\hline $\begin{array}{l}\Delta \mathrm{IV} \text { does not cause } \\
\text { Fitch actions }\end{array}$ & $\begin{array}{l}\text { LR-val. } \\
\text { p-val. }\end{array}$ & $\begin{array}{r}108.38 * * * \\
0.0008\end{array}$ \\
\hline $\begin{array}{l}\text { Fitch actions do not } \\
\text { cause } \Delta I V\end{array}$ & $\begin{array}{l}\text { LR-val. } \\
\text { p-val. }\end{array}$ & $\begin{array}{r}51.56 \\
0.9037\end{array}$ \\
\hline
\end{tabular}

This table reports the results from log-likelihood ratio tests after estimations of Equations (2) and (3). LR reports the log-likelihood ratio from the tests of null hypothesis that $\Delta \mathrm{IV}$ (Rating actions) do not cause Rating actions $(\Delta \mathrm{IV})$. p-val. reports the p-values from the tests. $* *, * * *$ denote significance at $5 \%, 1 \%$ levels. See Tables 1 and 2 for details on the data sample. 


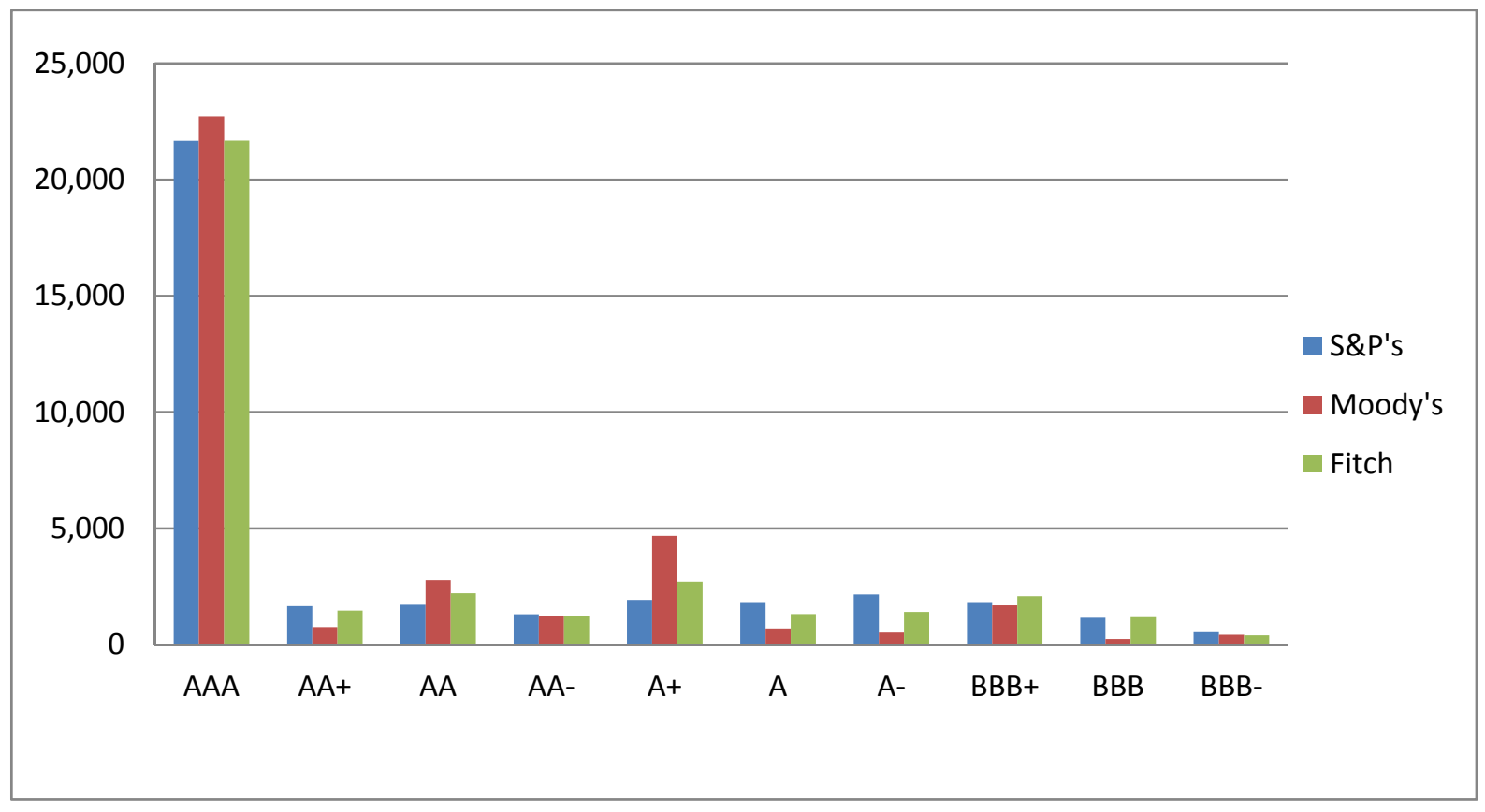

Fig. 1: Distribution of daily rating observations.

Moody's symbols (i.e. Aaa, Aa1, Aa2 ... Baa3) are categorised in equivalent S\&P and Fitch ratings categories (i.e. AAA, AA+, AA, ... BBB-). The dataset covers 24 countries during the period from January 2000 to April 2012. We include all countries with traded stock index options, except for 5 countries without any rating actions during the sample periods (Canada, Malaysia, Norway, Sweden and Switzerland) and Greece whose stock index option market is very small. 


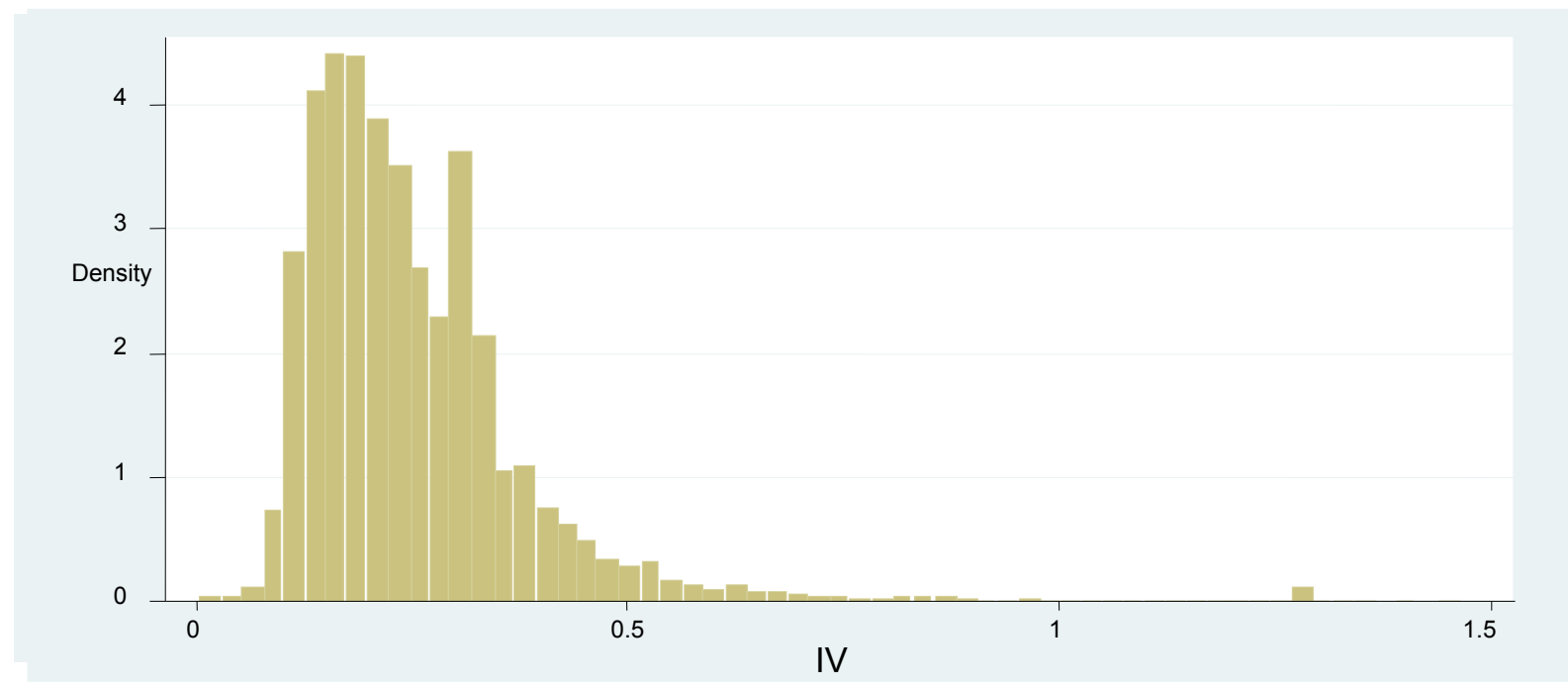

Fig. 2: Daily observations of 30-day maturity implied volatility.

The dataset covers 24 countries during the period from January 2000 to April 2012. There are 35,683 daily observations of 30-day implied volatility. Among them, there are 315 observations where IV is greater than $100 \%$ in Hungary (14/01/2003-16/6/2003), Poland (7/2001, 10-11/2001, 2-8/2002, 11/2002), and Russia (10/2008-4/2009). All (most) of these observations are associated within 1 month to at least one observation of absolute value of underlying index return larger than $1 \%(3 \%)$. $54 \%$ of the observations are associated with at least one observation of absolute value of the index return larger than $10 \%$. These were periods of turbulence in the three countries. There were nine rating signals on these three sovereigns during the periods. 


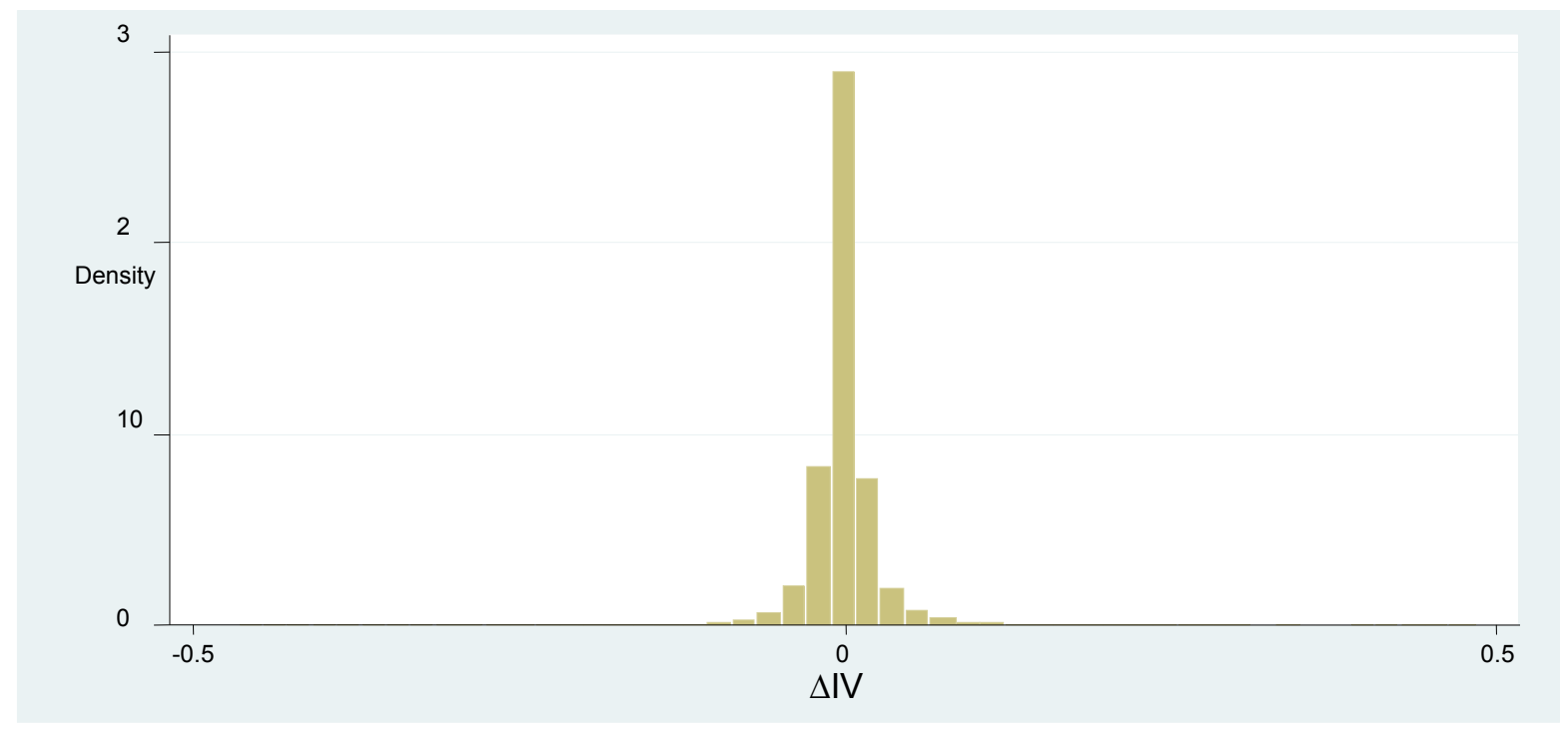

Fig. 3: Distribution of daily changes in 30-day implied volatility.

The dataset covers 24 countries during the period from January 2000 to April 2012. There are 115 observations where $\Delta \mathrm{IV}$ is more than $20 \%$. All (most) of them are associated within 1 month to at least one observation of absolute value of underlying index return larger than $1 \%(5 \%)$. 